\title{
S. cerevisiae Srs2 helicase ensures normal recombination intermediate metabolism during meiosis and prevents accumulation of Rad51 aggregates
}

\author{
Laura J. Hunt ${ }^{1,2} \cdot$ Emad A. Ahmed ${ }^{1,3} \cdot$ Hardeep Kaur ${ }^{4,5} \cdot$ Jasvinder S. Ahuja ${ }^{4} \cdot$ Lydia Hulme $^{1} \cdot$ Ta-Chung Chou ${ }^{1,6}$. \\ Michael Lichten ${ }^{4}$. Alastair S. H. Goldman ${ }^{1,7}$ (D)
}

Received: 16 January 2019 /Revised: 4 April 2019 / Accepted: 24 April 2019 /Published online: 9 May 2019

(C) The Author(s) 2019

\begin{abstract}
We investigated the meiotic role of Srs2, a multi-functional DNA helicase/translocase that destabilises Rad51-DNA filaments and is thought to regulate strand invasion and prevent hyper-recombination during the mitotic cell cycle. We find that Srs2 activity is required for normal meiotic progression and spore viability. A significant fraction of srs 2 mutant cells progress through both meiotic divisions without separating the bulk of their chromatin, although in such cells sister centromeres often separate. Undivided nuclei contain aggregates of Rad51 colocalised with the ssDNA-binding protein RPA, suggesting the presence of persistent single-strand DNA. Rad51 aggregate formation requires Spo11-induced DSBs, Rad51 strand-invasion activity and progression past the pachytene stage of meiosis, but not the DSB end-resection or the bias towards interhomologue strand invasion characteristic of normal meiosis. srs 2 mutants also display altered meiotic recombination intermediate metabolism, revealed by defects in the formation of stable joint molecules. We suggest that Srs2, by limiting Rad51 accumulation on DNA, prevents the formation of aberrant recombination intermediates that otherwise would persist and interfere with normal chromosome segregation and nuclear division.
\end{abstract}

Keywords Budding yeast $\cdot$ Meiosis $\cdot$ Recombination $\cdot$ Srs2 helicase $\cdot \operatorname{Rad} 51$

Laura J. Hunt and Emad A. Ahmed made equivalent contributions to this work.

This article is part of a Special Issue on Recent advances in meiosis from DNA replication to chromosome segregation 'edited by Valérie Borde and Francesca Cole, co-edited by Paula Cohen and Scott Keeney'.

Electronic supplementary material The online version of this article (https://doi.org/10.1007/s00412-019-00705-9) contains supplementary material, which is available to authorized users.

Alastair S. H. Goldman

a.goldman1@bradford.ac.uk

1 Department of Molecular Biology and Biotechnology, The University of Sheffield, Sheffield S10 2TN, UK

2 Present address: Genome Damage and Stability Centre, School of Life Sciences, University of Sussex, Brighton BN1 9RQ, UK

3 Present address: Immunology and Molecular Physiology Lab., Zoology Department, Faculty of Science, Assiut University, Markaz El-Fath 71515, Egypt
4 Laboratory of Biochemistry and Molecular Biology, Center for Cancer Research, National Cancer Institute, Bethesda, MD 20892, USA

5 Present address: Department of Biochemistry and Structural Biology, UT Health San Antonio, San Antonio, TX 78229, USA

6 Present address: All First Tech Co., Ltd, 32467, No 146-2. Hung Chun Road, Ping Zhen Dist, Taoyuan City, Taiwan

7 Faculty of Life Sciences, The University of Bradford, Bradford BD7 1AZ, UK 


\section{Introduction}

The production of haploid gametes during meiosis requires the ordered segregation of the diploid genome, such that each chromosome is present as a single copy in daughter cells. This occurs through two successive nuclear divisions (meiosis I and meiosis II) that follow a single round of DNA replication. In most organisms, homologous chromosomes of different parental origin (called homologues), each comprising two sister chromatids held together by cohesin, are first paired and then synapsed end-to-end by a structure called the synaptonemal complex (SC; reviewed in Heyting 1996). Homologues become covalently linked by crossovers (COs), and this linkage allows their correct orientation on the meiosis I spindle, so they segregate to opposite poles during the first meiotic nuclear division. Sister chromatids are subsequently separated during meiosis II. In most eukaryotes, homologous recombination (HR) is critical during meiosis, both for the pairing and synapsis processes that bring homologues together, and for the formation of crossovers that allow their correct segregation (reviewed in Petronczki et al. 2003).

Meiotic HR is initiated by DNA double-strand breaks (DSBs), formed by the Spo11 protein (Keeney et al. 1997). DSBs are resected, in a process dependent on Sae2/Com1 (McKee and Kleckner 1997; Prinz et al. 1997) to form 3' single-stranded DNA (ssDNA) capable of a homology search. During the mitotic cell cycle, HR requires the strand exchange protein Rad51, which displaces the ssDNA-binding RPA protein complex and mediates strand invasion into homologous duplex DNA (reviewed in Morrical 2015). The invading single strand displaces a strand of the homologous duplex and primes DNA synthesis to form a displacement loop (D-loop). D-loop collapse, followed by reannealing to ssDNA at the other break end, forms exclusively noncrossover (NCO) products in a process called synthesis-dependent strand annealing (SDSA; Nassif et al. 1994). Alternatively, capture of the second ssDNA by the D-loop forms a double Holliday junction $(\mathrm{dHJ})$ intermediate, which can be resolved either as an NCO or as a CO (Szostak et al. 1983). During the mitotic cell cycle, most Rad51-mediated HR occurs between sister chromatids (Bzymek et al. 2010; Kadyk and Hartwell 1992), and events that involve homologues produce NCOs, rather than COs (Ira et al. 2003; Lichten and Haber 1989), thus reducing the risk of genome rearrangement and loss of heterozygosity.

In contrast, interhomologue COs are an important outcome of HR during meiosis, since they mediate proper homologue orientation and segregation. In many organisms, including budding yeast, meiosis-specific modifications of recombination encourage both strand invasion between homologues and production of a higher proportion of COs. This involves the expression of a second strand exchange protein, Dmc1 (Bishop et al. 1992). Rad51 is still present in meiotic cells, and is an essential cofactor for normal Dmc1 loading and strand invasion activity (Cloud et al. 2012). However, in budding yeast, Rad51 strand exchange activity is dispensable for recombination (Cloud et al. 2012), and is negatively regulated during meiosis by at least two known mechanisms involving the meiosis-specific kinase Mek1. Mek1 kinase is activated by binding to a phosphorylated form of the meiotic chromosome axis protein Hop1 (Niu et al. 2005), which is formed in the vicinity of meiotic DSBs by DNA damage response kinases (Carballo et al. 2008). Active Mek1 phosphorylates Rad54, a protein required for Rad51 to form stable strand invasion products, and prevents Rad54-Rad51 interaction (Niu et al. 2009). Mek1 also phosphorylates and stabilises the meiosisspecific Hed1 protein, which binds to Rad54 and prevents it from interacting with Rad51 (Callender et al. 2016).

Rad51 is also negatively regulated by the budding yeast Srs2 protein, a $3^{\prime}$ to $5^{\prime}$ DNA helicase/translocase of the UvrD family (reviewed in Niu and Klein 2017). Srs2 interacts with Rad51 filaments in vitro and strips them from DNA (Kaniecki et al. 2017; Krejci et al. 2003; Veaute et al. 2003). Loss of Srs2 activity in mitotic cells leads to DNA damage sensitivity, genome instability, reduced DSB repair efficiency and an increase in COs among repair products (Elango et al. 2017; Ira et al. 2003; Lawrence and Christensen 1979; Marini and Krejci 2010; Rong et al. 1991). As srs2 sensitivity to DNA damage is partially suppressed by deletion of RAD51, it is thought that srs 2 mutant phenotypes relate to failures in Rad51 removal from ssDNA (Ira et al. 2003; Krejci et al. 2003). Srs 2 also unwinds branched DNA structures in vitro, including those mimicking D-loop recombination intermediates, consistent with a role in promoting SDSA (Dupaigne et al. 2008; Kaniecki et al. 2017; Liu et al. 2017; Marini and Krejci 2012). However, this function has yet to be fully investigated in vivo. In meiosis, Srs2 activity is required for normal spore viability and meiotic progression, and $s r s 2 \Delta$ mutants show reduced formation of COs and NCOs (Palladino and Klein 1992; Sasanuma et al. 2013a; b).

We have analysed further the importance of Srs2 function during meiosis and found that it is required for normal recombination intermediate metabolism and nuclear division. In srs 2 mutants, Rad51 protein appears in aggregates after exit from pachytene, when the SC has been dissolved. These Rad51 aggregates are often associated with RPA, and arise only if programmed DSBs are formed and if Rad51 has full-strand exchange capability. srs 2 mutants show partial defects in meiotic nuclear divisions, but cytological investigation of chromosomal segregation implies that sister centromere separation occurs normally. These data suggest that $\operatorname{srs} 2$ mutants suffer entanglements caused by abnormal interhomologue recombination intermediates. Consistent with this, we found evidence for defects in formation of stable interhomologue recombination intermediates. We propose that loss of Srs2-mediated negative regulation of Rad51 allows for defects in DNA 
interactions during pachytene, which later lead to defects that prevent normal nuclear division.

\section{Results}

\section{Sporulation is delayed and reduced in srs 2 mutants, with decreased spore viability}

Known meiotic defects caused by loss of Srs 2 activity include nuclear division defects, reduced sporulation and reduced spore viability (Palladino and Klein 1992). We confirmed these phenotypes in our srs 2 mutant strains, which included: $s r s 2 \Delta$, which produces no Srs2 protein; srs2-101, which is mutated in the predicted ATP-binding site (Rong et al. 1991); and $s r s 2-m d$, a replacement of the endogenous $S R S 2$ promoter with the $C L B 2$ promoter, where $S R S 2$ is expressed in mitotic cells but not during meiosis (Chu et al. 1998).

All three srs 2 mutants showed meiotic nuclear division defects. The fraction of cells completing both meiotic nuclear divisions was reduced from $94 \%$ in $S R S 2$ strains to 60,59 and $60 \%$, respectively, in cells homozygous for $s r s 2-m d$, srs2-101 and $s r s 2 \Delta$. In addition, nuclear division was delayed by approximately $1 \mathrm{~h}$, and a substantial fraction ( $20 \%)$ of srs 2 mutant cells completed only one of the two nuclear divisions (Fig. 1a-e). Incomplete nuclear division could also be observed in srs 2 strains, with nuclei remaining connected by chromosome bridges at times when nuclear division was complete in wild type (Fig. 1f). Spore viability is reduced in cells that complete meiosis, from $98 \%$ in wild type to $63-68 \%$ in srs 2 mutants (Fig. $1 \mathrm{~g})$. Tetrad spore death patterns typical of defects specific to either meiosis I or meiosis II were not observed, suggesting that segregation failure is not specific to a single stage of meiosis (Fig. 1h).

\section{The spindle cycle continues in srs 2 mutants despite nuclear division defects}

During each round of meiosis, the spindle pole body (SPB, budding yeast centrosome equivalent) must duplicate, divide and migrate to opposite poles of the cell in order for the dividing chromosomes to be correctly drawn along the tubulin spindles at anaphase. Duplicated SPBs are initially connected by a bridge (Byers and Goetsch 1975), and spindle separation is controlled by activity of the cyclindependent kinase Cdc28/Cdk1 (Jaspersen et al. 2004). During the meiosis I to meiosis II transition, SPBs must be relicensed for duplication in a process regulated by the Cdc14 phosphatase (Fox et al. 2017). Thus, analysis of SPB division provides a useful indicator of meiotic cell cycle progression.
To monitor SPB division, we examined spread cells from strains expressing fluorescently tagged SPB (Cnm67-mCherry) and spindle proteins (GFP-Tub1), neither of which altered meiotic progression (Supplementary Fig. S2b). Cells were classified by number of SPB signals, as for nuclear division (Fig. 2a). As expected, due to SPB division preceding nuclear division, cells with two, three or four SPBs appeared slightly less than $1 \mathrm{~h}$ before cells with the same number of nuclei, with $96 \%$ of cells completing two SPB divisions by $9 \mathrm{~h}$ post-induction of meiosis (Fig. $2 \mathrm{~b}, \mathrm{c})$. In the srs 2-101 strain, cells that had accomplished SPB division and separation increased with wild-type timing until $6 \mathrm{~h}$ and then increased only slightly. By $9 \mathrm{~h}$, more than $75 \%$ of cells had produced at least two separated SPBs, while only $60 \%$ of cells had completed the meiosis I nuclear division (Fig. 2b) and about $35 \%$ of cells had failed to complete the two SPB and nuclear divisions (Fig. 2c). Most notably, a significant population of srs 2 cells had divided SPBs but contained only an undivided nuclear signal. The fraction of cells with this phenotype reached a maximum at $6 \mathrm{~h}$, with 32 and $24 \%$ of $\operatorname{srs} 2-101$ and $\operatorname{srs} 2 \Delta$ cells, respectively, compared with $8.0 \%$ in wild type (Fig. 2e). This observation, that loss of Srs2 activity results in a significant population of cells with divided SPBs but undivided nuclei, suggests that these cells are attempting to progress through meiosis II despite the nucleus failing to divide correctly in meiosis I. However, it should also be noted that about a quarter of the population does not undergo even the first round of meiotic SPB separation.

\section{Sister centromeres separate in the absence of Srs2, despite failures in nuclear division}

To investigate the nature of the nuclear division failure in srs 2 strains, we monitored sister chromatid separation, using strains that expressed a fusion between the Tet repressor and GFP (TetR-GFP) and that were heterozygous for a Tet operator array (tet $O, 224$ repeats) inserted near the centromere of chromosome V. In such strains, the separation of the tetO/TetR signals is a proxy for sister centromere separation. In wild-type cells, a single signal is visible until meiosis II, when this signal divides into two signals, which then segregate into two of the four nuclei present at the tetranucleate stage (Fig. 3a).

Cells with divided SPBs but one nucleus (i.e. class IIIb cells, see Fig. 2d) were analysed for tetO/TetR signal separation. Interestingly, most class IIIb cells in the srs 2-md strain had two tetO/TetR signals, despite the nucleus failing to divide (Fig. 3b, c). Although fewer wild-type cells displayed single nuclei at late time points in meiosis, it is notable that the tet $O /$ TetR signals in these cells also were usually separated. This suggests that even when nuclear division fails, the majority of sister centromeres are 

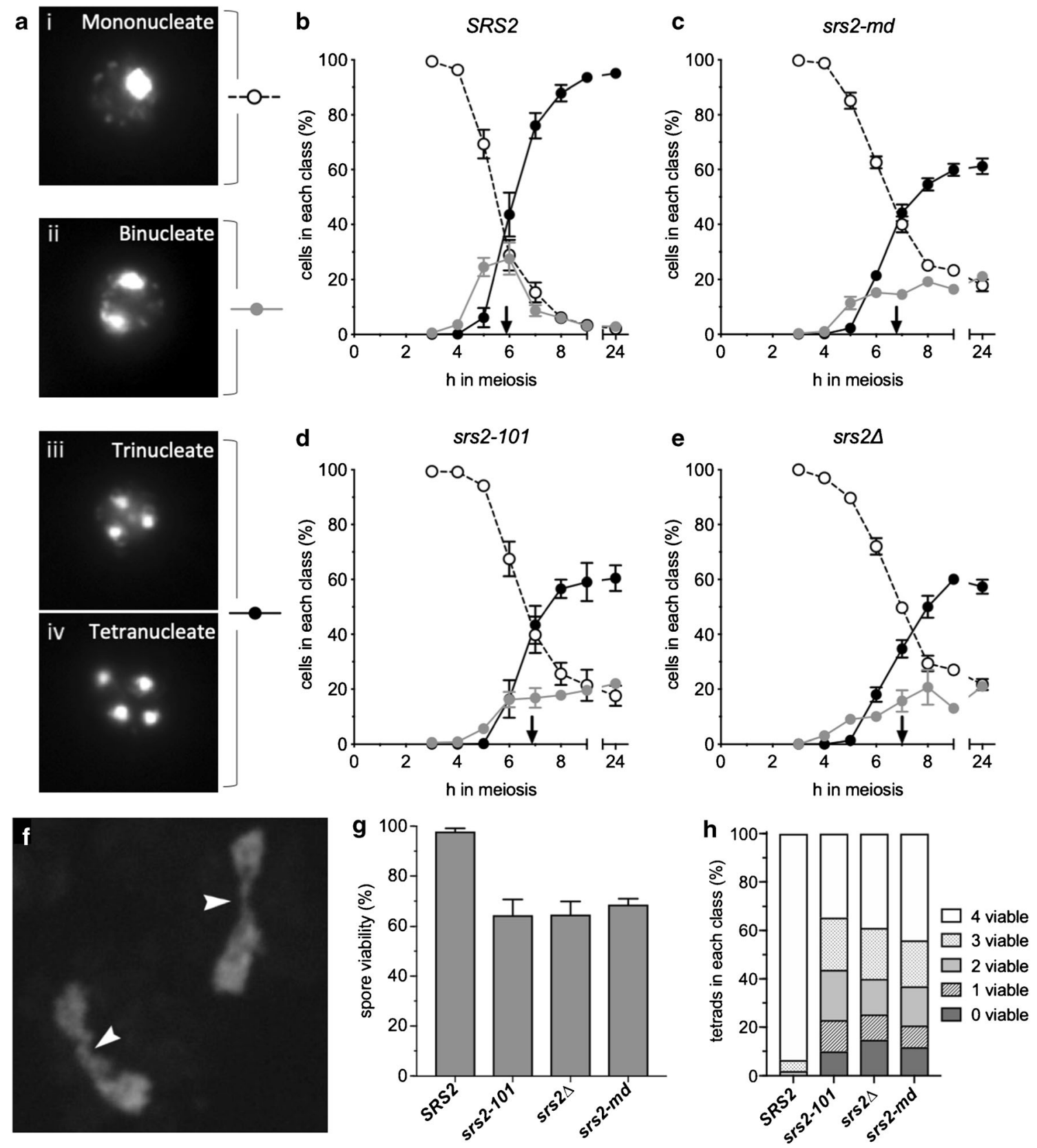

Fig. 1 Sporulation defects caused by loss of Srs2 activity. a Examples of nuclear morphology. Symbols alongside each panel correspond to symbols used in graphs. b-e Meiotic progression. b In SRS2 strains, about $95 \%$ of cells progress through the two meiotic nuclear divisions. c-e Progression through nuclear divisions is reduced to about $60 \%$ compared with wild type and is delayed by $\sim 1 \mathrm{~h}$; vertical arrows on $x$ axis indicate when $40 \%$ of cells had completed meiosis II. srs 2 mutants also display persistent binucleate cells. SRS2, $n=7 ; \operatorname{srs} 2-m d, n=9$; srs2-

separating correctly, at least where measured close to pericentromeric DNA on chromosome V. Similar analysis of a strain with homozygous tet $O$ inserts also indicates that 4 SPB signals are frequently observed in $s r s 2$ strains (EAA and ASHG, unpublished observations), suggesting that centromeres on both homologous chromosomes and sister chromatids separate.
$101, n=5 ; \operatorname{srs} 2 \Delta, n=3$; error bars-standard error of the mean. $\mathbf{f}$ DNA bridges observed in $\operatorname{srs} 2$ mutants (example from $9 \mathrm{~h}, s r s 2-101$ ). $\mathbf{g}$ Reduced spore viability in $s r s 2$ mutants. $\mathbf{h}$ Patterns of spore viability in tetrads from $s r s 2$ mutants are inconsistent with either meiosis I or meiosis II nondisjunction. SRS2, $n=5,159$ tetrads total; $\operatorname{srs} 2-101, n=2,99$ tetrads; srs $2 \Delta, n=2,100$ tetrads; srs $2-m d, n=3,139$ tetrads; error bars in (g) indicates range

\section{Loss of Srs2 function in meiosis leads to Rad51 aggregate formation}

As Srs2 is thought to regulate mitotic recombination by removing Rad51 from ssDNA nucleoprotein filaments and allowing repair by SDSA (Andersen and Sekelsky 2010), we hypothesised that the meiotic nuclear division 

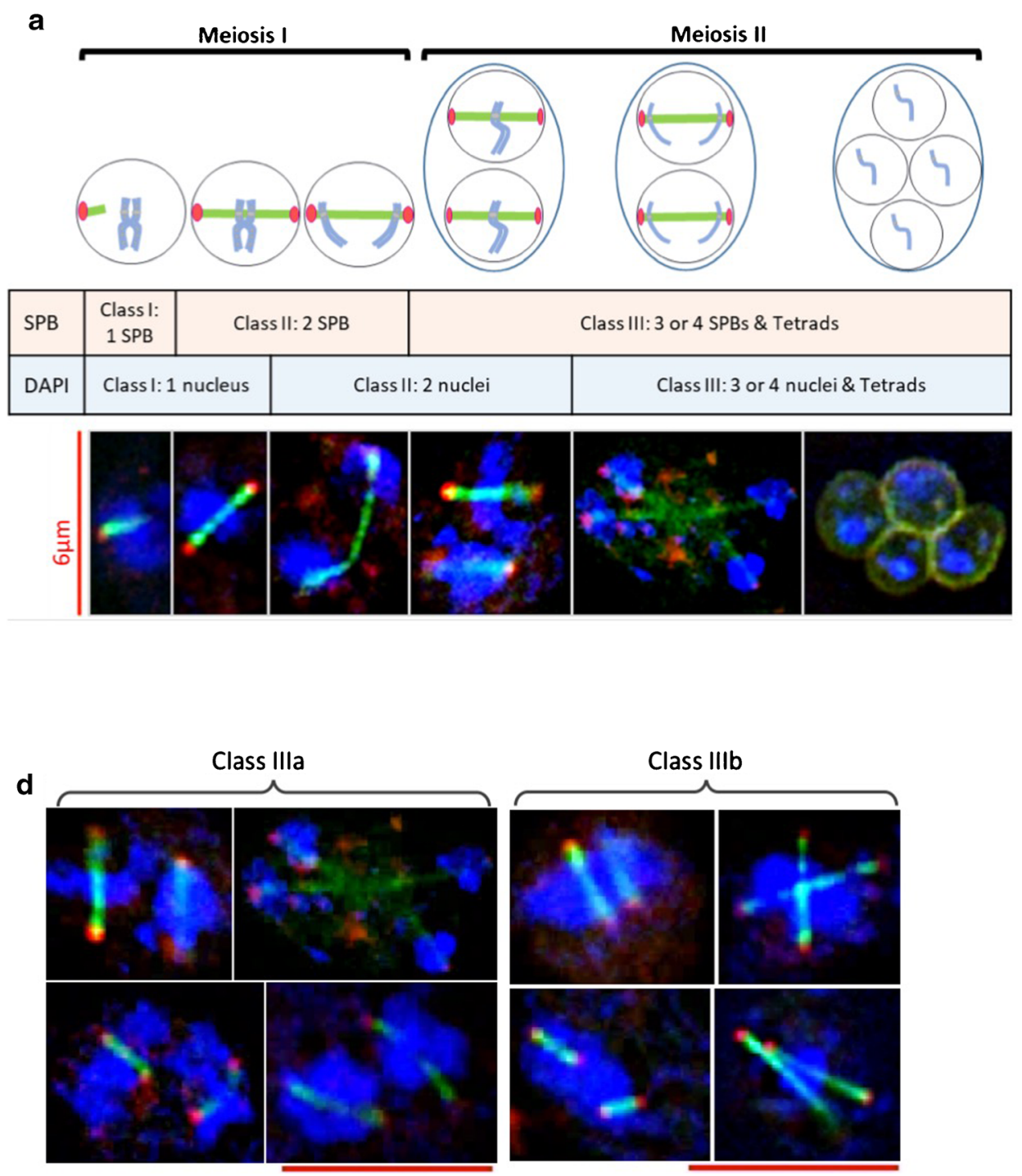

Fig. 2 Altered nuclear division and spindle dynamics in the absence of Srs2 activity. a Classifications used during analysis of spindle pole body (SPB) and nuclear (DAPI) division. $\mathbf{b}, \mathbf{c}$ Fraction of cells completing both meiotic nuclear (blue) or SPB divisions. Unlike nuclear division (see also Fig. 1), SPB division is not delayed in srs2-101 (nuclear division data from Fig. 1; SPB analysis, $n=2$; error bars - range). d Combining nuclear and SPB analysis reveals two distinct populations of cells that have

failure seen in $s r s 2$ cells may be due to entanglements caused by a failure to remove $\operatorname{Rad} 51$. We therefore analysed Rad51 distributions in nuclear spreads using immunofluorescence. Cells were classed into three groups: those with no Rad51 signal; those with only small Rad51 signals $(<0.39 \mu \mathrm{m}$ in any direction $)$, hereafter called 'Rad51 foci'; and those with large Rad51 signals (> $0.39 \mu \mathrm{m})$, which we here refer to as 'Rad51 aggregates' (Fig. 4). srs $2-m d$ mutants were observed to accumulate Rad51 aggregates at later times during meiosis ( $4 \mathrm{~h}$ onward); these aggregates were rarely seen in wild-type cells (Fig. 4c). Similar Rad51 aggregate accumulation is observed in srs2-101 (Supplementary Fig. S2b) and in (Fig. 4b). the absence of Srs2.
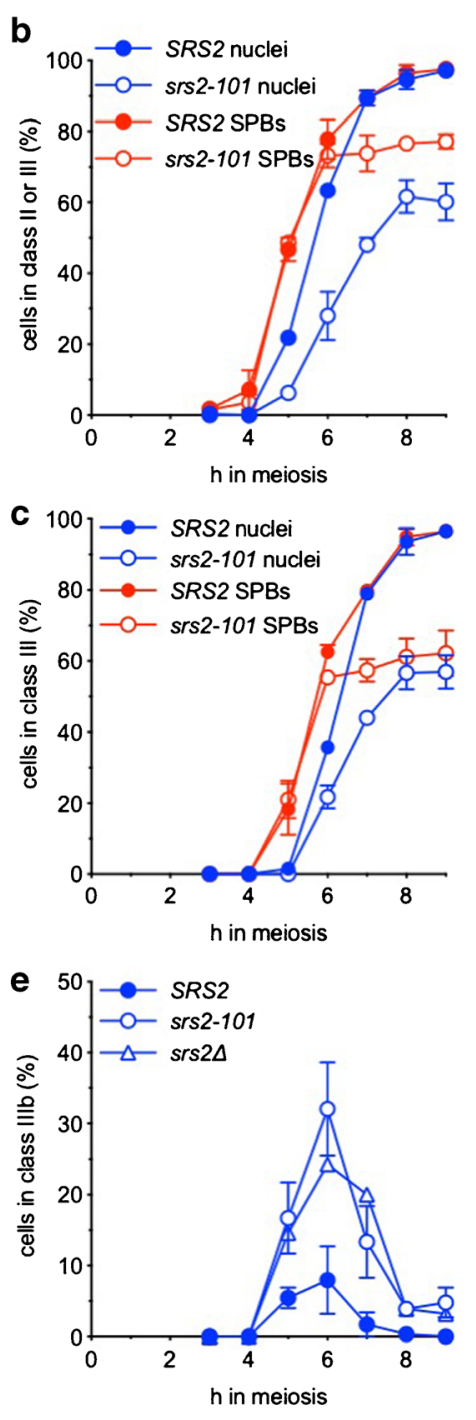

completed both SPB divisions: class IIIa, cells with at least two nuclei, as expected for cells with divided SPBs, and class IIIb, cells with only a single nucleus, despite having divided SPB signals. Scale bar, $6 \mu \mathrm{m}$. e Loss of Srs 2 activity is associated with an increased frequency of class IIIb nuclei, which have completed SPB division but have failed to divide nuclei (SRS2, $n=2 ; \operatorname{srs} 2-101, n=2 ; \operatorname{srs} 2 \Delta, n=1$; error bars-range)

$\operatorname{srs} 2 \Delta$ mutants (Sasanuma et al. 2019). A substantial fraction of srs 2 cells also display persistent Rad51 foci, at times when these foci have disappeared from wild type

Meiotic DSB formation requires Spo11 transesterase activity, which is abolished by loss of the reactive $\mathrm{OH}$ group at the catalytic tyrosine $(s p o 11-Y 135 F)$. Both aggregate formation (Fig. 4c) and nuclear division defects of $s r s 2$ mutants are suppressed by spoll mutation (Supplementary Fig. S2a, Sasanuma et al. 2019), indicating that both Rad51 aggregates and barriers to nuclear division form as a consequence of abnormal DSB repair in 

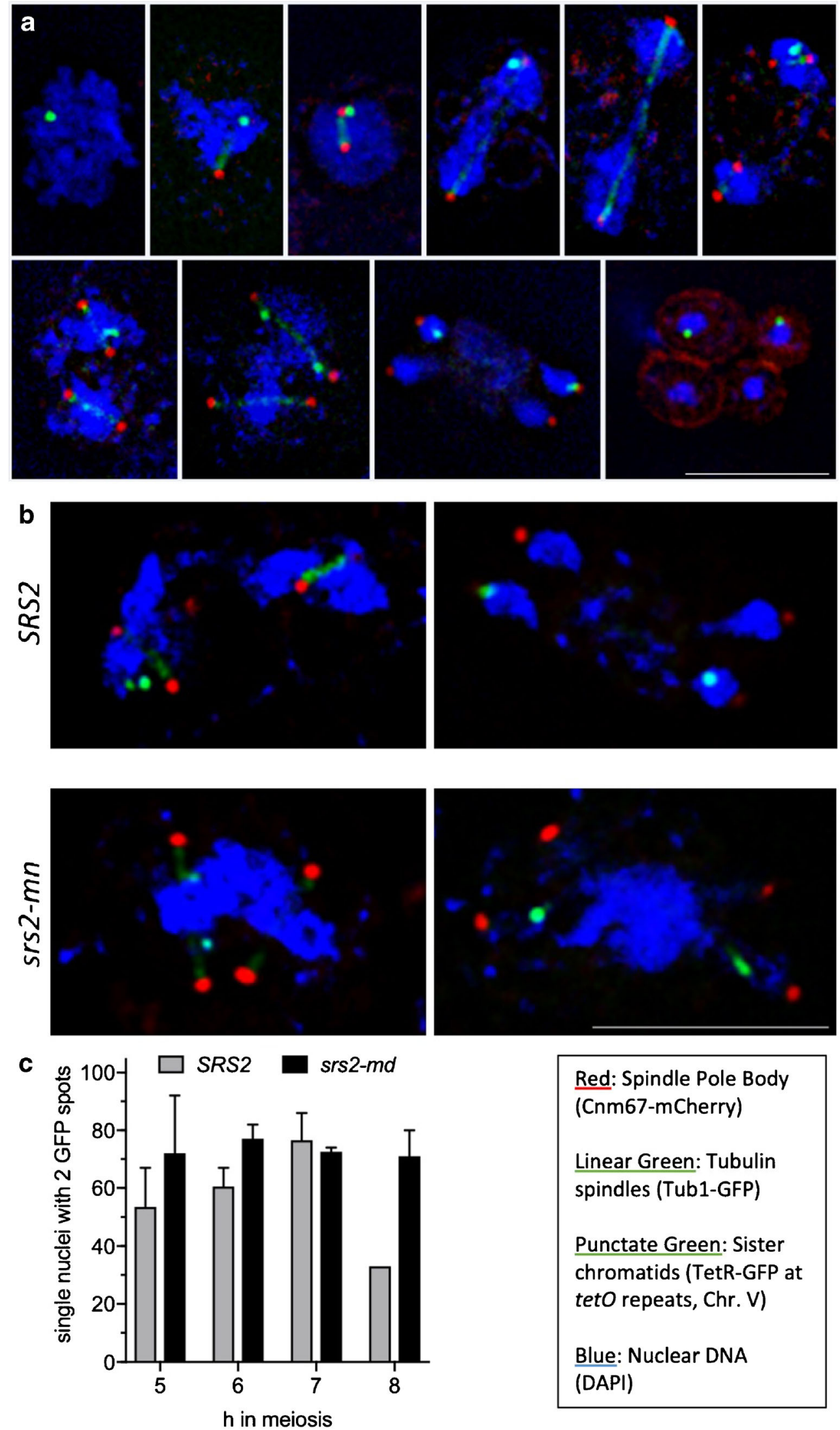

Red: Spindle Pole Body (Cnm67-mCherry)

Linear Green: Tubulin spindles (Tub1-GFP)

Punctate Green: Sister chromatids (TetR-GFP at tetO repeats, Chr. V)

Blue: Nuclear DNA (DAPI) 
Fig. 3 Sister chromatid separation observed during meiosis using a tet repressor-GFP fusion and heterozygous tet operon repeats at the URA3 locus. a Representative images showing progression of sister chromatid segregation through meiosis in wild-type cells. Scale bar, $5 \mu \mathrm{m}$. b Representative images of SRS2 (6 and $7 \mathrm{~h}$ ) and srs2-md (6 and $8 \mathrm{~h}$ ) cells with divided spindle pole bodies. Even when the nucleus fails to divide, separated tetO/TetR signals can be observed suggesting sister chromatids have separated. Scale bar, $5 \mu \mathrm{m}$. c Percent of mononucleate cells that have divided SPBs and contain divided TetR-GFP signals (i.e. class IIIb cells, see Fig. 4e). $n=2$, except for $S R S 2$ at $8 \mathrm{~h}$ for which class IIIb cells were only observed in one experiment; error bars denote range

\section{Meiotic phenotypes of srs2 depend on Rad51-mediated strand invasion}

Rad51 protein has two activities with the potential to contribute to aggregate formation during meiosis in $s r s 2$ mutants. Rad51 forms a filament on ssDNA, which then catalyses invasion of homologous duplex DNA through a second DNA binding site. rad51-II3A mutants, which lack this second binding site, are competent for filament formation but defective in strand invasion (Cloud et al. 2012). During meiotic recombination in budding yeast, $\operatorname{Rad} 51$ acts as a co-factor in filament assembly but not strand invasion with a meiosisspecific homologue, Dmc1, and rad51-II3A mutants are competent for meiotic DSB formation and homologous recombination (Cloud et al. 2012). If the phenotypes observed in $\operatorname{srs} 2$ mutants were due to a defect in removing Rad51 from meiotic recombination intermediates, then aggregates should still form in srs 2 rad51-II3A double mutants. Because rad51-II3A and srs $2-101$ or $s r s 2 \Delta$ mutants are synthetically lethal (T-CC, EAA and ASHG, unpublished observations), we combined the meiotic-depletion $s r s 2-m d$ allele with rad51-II3A. Only $\sim 4 \%$ of srs $2-m d$ rad51-II3A cells contained Rad51 aggregates, as compared to $15-25 \%$ of srs $2-m d$ RAD51 cells (Fig. 5b). This indicates that aggregate formation depends on Rad51's ability to bind a second DNA molecule, rather than retention of Rad51 filaments. Since Rad51 strand
Fig. 4 Mutants lacking Srs2 activity form Rad51 aggregates. a Detection of Rad51 in nuclear spreads; blue, DAPI/DNA; red, $\alpha$-Rad51. Cells were categorised as: (i) cells with no Rad51 signal, (ii) cells with Rad51 foci and (iii) cells with large Rad51 aggregates. Scale bar, $5 \mu \mathrm{m}$. b srs 2 mutants show a persistent Rad51 signal (either foci or aggregates). c $s r s 2$ mutants display Spo11-dependent Rad51 foci. d srs 2 mutants display Spo11-dependent Rad51 aggregates. (SRS2, $n=3$; srs 2 $m d, n=5$; srs $2-m d$ spo $11, n=1$; error bars - standard error of the mean)
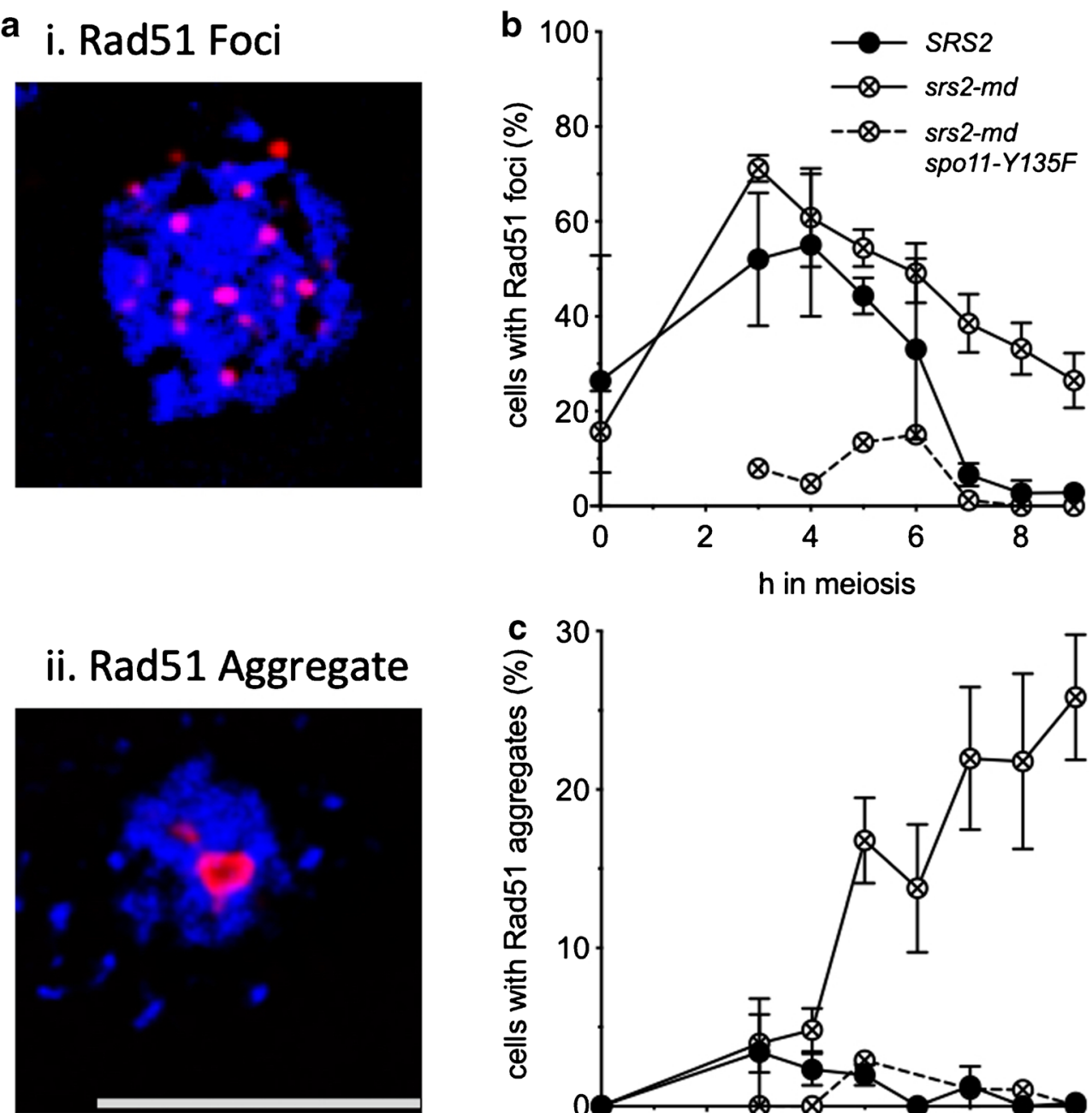

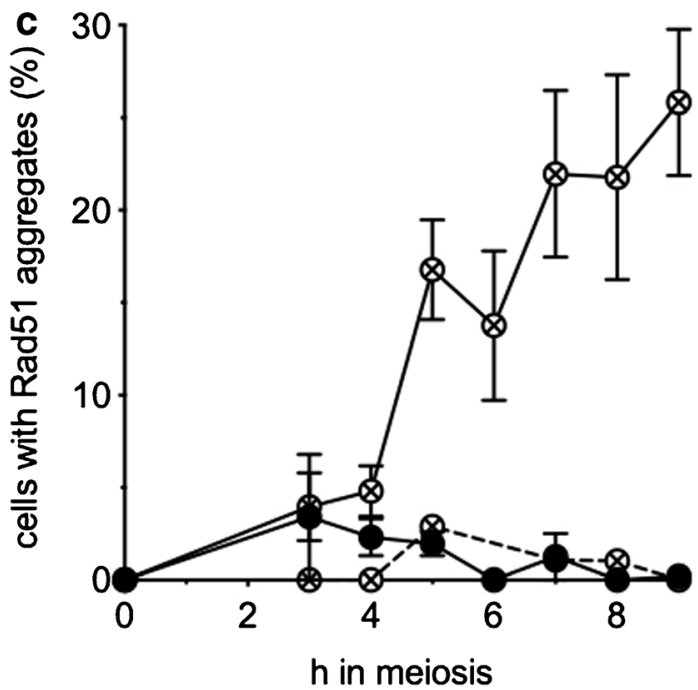



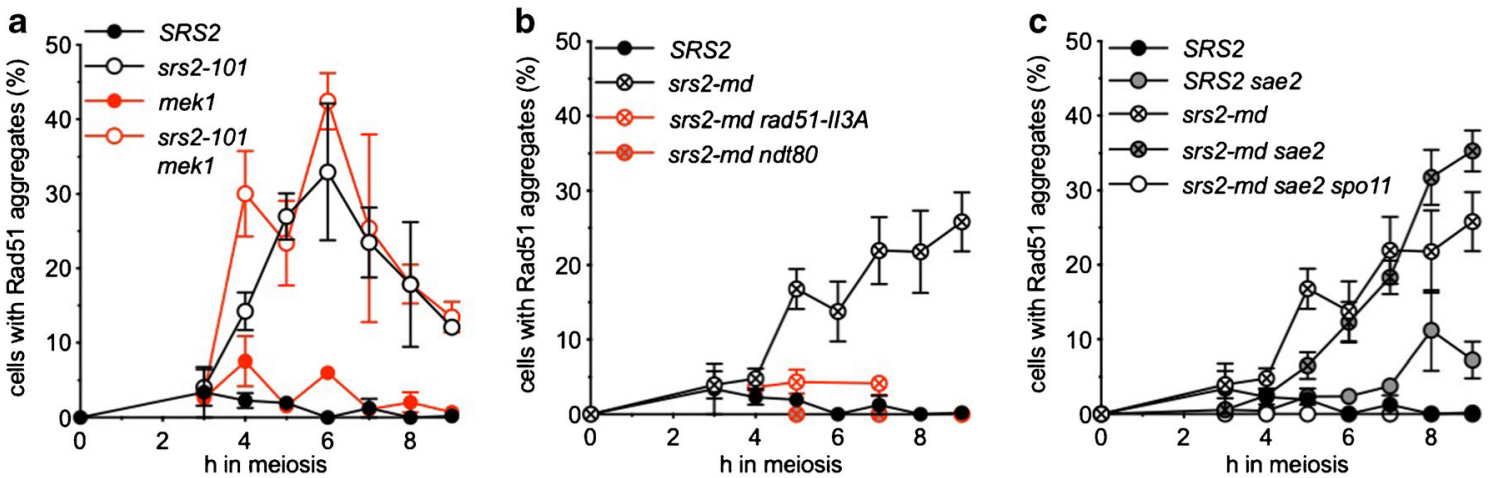

Fig. 5 Analysis of the Rad51 aggregation phenotype. a Deletion of $M E K 1$ does not suppress aggregate formation, indicating that an interhomologue bias for strand invasion is not required. b Rad51 aggregates do not form in rad51-II3A or $n d t 80 \Delta$ mutants, indicating that both Rad51-mediated strand invasion and exit from pachytene are required for aggregate formation. c Deletion of $S A E 2$ does not prevent aggregate formation, suggesting that normal DSB processing is not

required. Interestingly, a small fraction of sae $2 \Delta$ cells form aggregates at later time points in a SPO11-dependent manner. (SRS2, $n=3 ; s r s 2-101$, $n=3$; srs2-101 mekl $\Delta, n=2 ;$ mekl $\Delta, n=2 ;$ srs2-md, $n=5$; srs2-md $n d t 80 \Delta, n=1 ; \operatorname{srs} 2-m d$ rad51-II3A, $n=3 ; \operatorname{srs} 2-m d$ sae $2 \Delta, n=4$; $\operatorname{sae} 2 \Delta, n=3)$. Error bars - standard error of the mean, except for srs2-

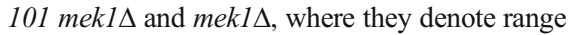

exchange activity is not normally required for meiosis, this suggests that Rad51 aggregates derive from 'off-pathway' events, rather than from normal meiotic recombination intermediates.

\section{Rad51 aggregation is independent of MEK1-dependent interhomologue bias}

To test whether Rad51 aggregates that form in srs 2 mutants arise from normal interhomologue meiotic recombination intermediates, we examined mutants lacking Mek1, a meiosisspecific kinase that is a major effector of the bias towards use of the homologue, rather than the sister chromatid, during meiotic DSB repair (Niu et al. 2005). Deletion of MEK1 did not rescue the aggregation phenotype of srs2-101 mutants, suggesting Rad51 aggregates are not caused by a failure in the processing or resolution specifically of interhomologue recombination intermediates (Fig. 5a).

\section{Rad51 aggregate formation is independent of Sae2}

As Rad51 aggregate formation depends on Spo11-DSB formation and the ability of Rad51 to bind a second DNA molecule, we hypothesised that Rad51 aggregation should also be dependent on DSB resection. To test this, we performed analysis in cells lacking Sae2, which is required for normal resection of Spo11-induced DSBs prior to strand invasion. Surprisingly, however, deletion of $S A E 2$ did not prevent the formation of aggregates, which at late time points were instead slightly increased in srs2-md sae $2 \Delta$ double mutants compared to $s r s 2-m d$ alone (Fig. $5 \mathrm{c}$ ). Rad51 aggregates were also observed in sae2 $\triangle S R S 2$ cells at later time points, all be it at lower levels (Fig. 5c), and these aggregates were also Spo11 dependent (data not shown). The proportion of aggregates seen at late time points in srs2-md sae $2 \Delta$ double mutants reflected the sum of levels seen in the single mutant cells, consistent with an independent contribution from the two single mutations (Fig. 5c). Thus, Rad51 aggregate formation does not require normal meiotic DSB resection.

\section{Rad51 aggregates form after exit from pachytene}

Since analysis of srs 2 rad51-II3A and srs 2 mekl double mutants suggested that Rad51 aggregates form as the consequence of abnormal meiotic recombination, it was of interest to determine the stage of meiosis at which aggregation occurs. Rad51 immunofluorescence was combined with visualisation of the synaptonemal complex (SC) using GFP-tagged Zip1 (White et al. 2004), a component of the tripartite structure that forms along the length of homologous chromosomes during the pachytene stage of meiotic prophase and provides a framework that assists the process of homologous recombination (Heyting 1996; Yang and Wang 2009). Once recombination is completed, cells exit pachytene in a process that requires gene expression driven by the $\mathrm{Ndt} 80$ transcription factor (Chu and Herskowitz 1998). The SC is disassembled and recombination intermediates resolve, leaving the crossover products of recombination to maintain connections between homologues (Sourirajan and Lichten 2008; Zickler and Kleckner 1999, 2016). As expected, Rad51 foci were found in wild-type cells with either Zip1 foci or long regions of synapsis, but were absent from cells lacking Zip1 signal. However, srs 2 mutants displayed Rad51 foci in Zip1-positive cells and prominent Rad51 aggregates in cells that lacked any Zip1 signal, suggesting that aggregates form after cells exit pachytene (Fig. 6). To confirm this, we examined $n d t 80 \Delta$ mutants, which arrest in pachytene with fully synapsed homologues and duplicated but unseparated SPBs (Xu et al. 1995). Rad51 aggregates were absent from both $s r s 2-m d n d t 80 \Delta$ cells (Fig. 5b) and srs2-101 ndt80 cells (data not shown) at all times. These results indicate that, in srs 2 mutants, Rad51 aggregate 
Fig. 6 Analysis of Rad51 aggregates in cells expressing Zip1-GFP, a synaptonemal complex protein. a Representative images of $\operatorname{srs} 2$ 101 cells with punctate or elongated Zip1-GFP signals (3 and $5 \mathrm{~h}$, respectively) with clear Rad51 foci. b Representative images of Zip1-negative srs2-101 cells at $5 \mathrm{~h}$. Cells can be classified as having no Rad51 signal, large aggregates of Rad51 or elongated thread-like aggregates of Rad51. Aggregates of Rad51 can be observed in srs2-101 cells in the absence of a synaptonemal complex
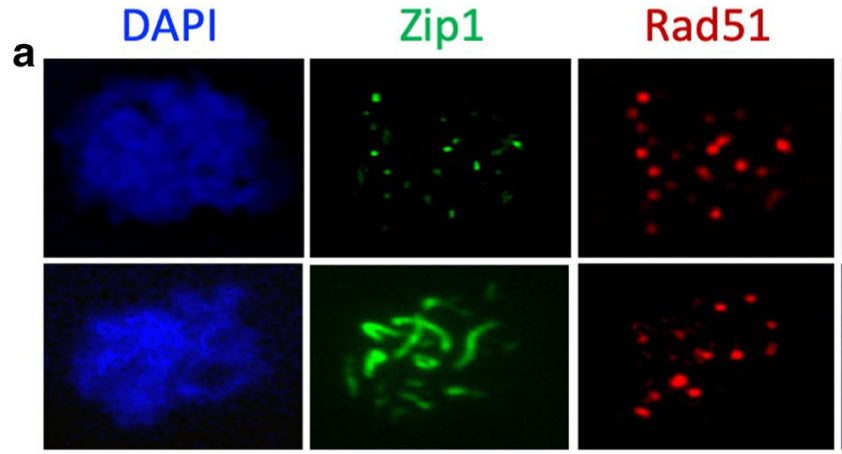

Merge
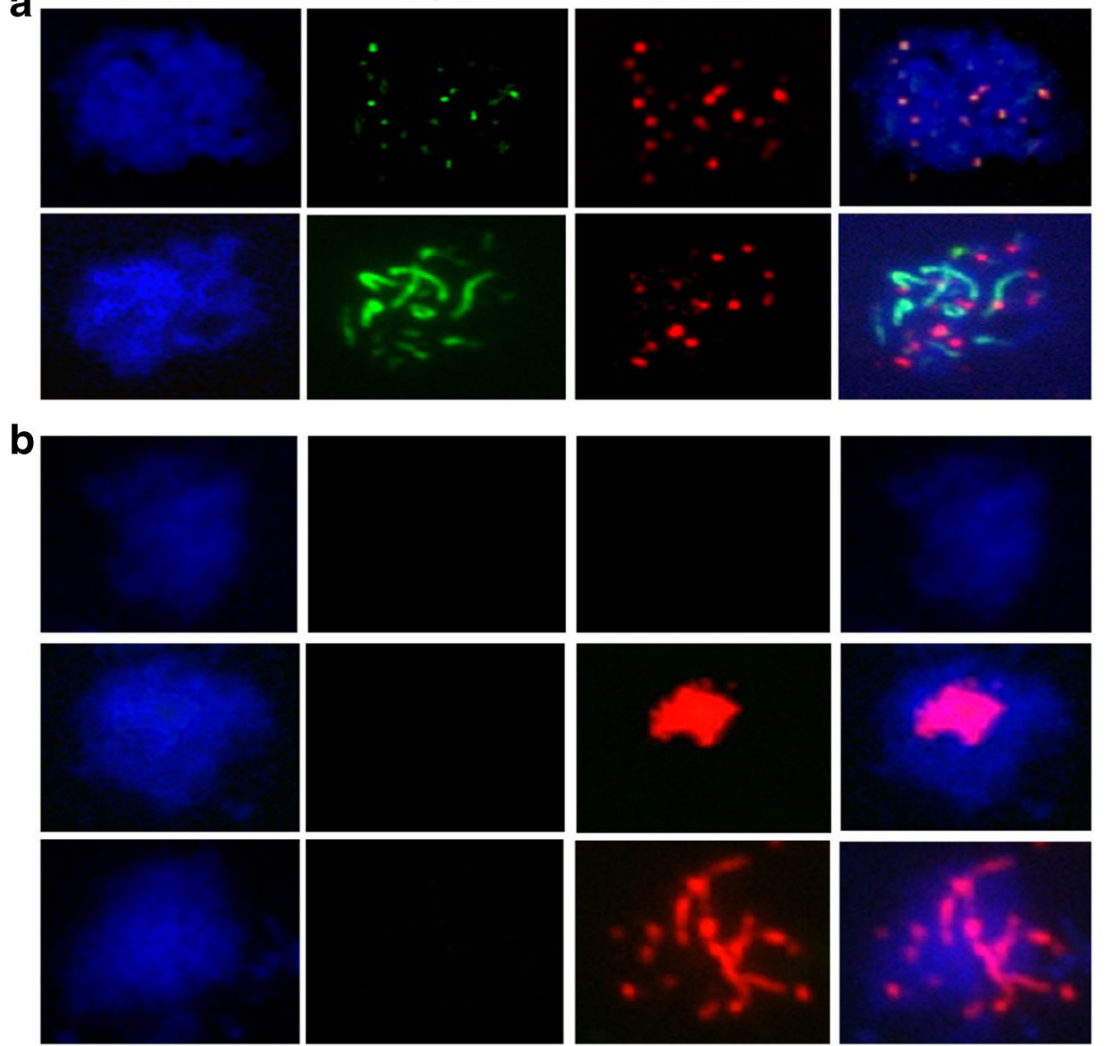
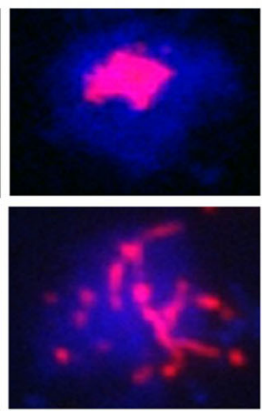

formation occurs after the cells exit from pachytene, and thus after meiotic recombination would be complete in wild-type cells.

\section{RPA colocalises with Rad51 aggregates}

The ssDNA that is formed by DSB resection is initially coated with replication protein A (RPA), a heterotrimeric complex that is essential for viability (Brill and Stillman 1991; Chen et al. 2013). Although RPA binding to ssDNA is important for formation of active Rad51 filaments, RPA is displaced during filament formation. Thus, $\operatorname{Rad} 51$ and RPA foci are at times adjacent to each other but rarely are truly colocalised (Gasior et al. 1998; Hays et al. 1998). However, a substantial fraction of Rad51 aggregates that form in $s r s 2-m d$ colocalise with either a focus or an aggregate of RPA (Fig. 7a, b). Detailed analysis of Rad51 and RPA signals at $5 \mathrm{~h}$ post-induction of meiosis in srs2-md cells confirmed that foci of RPA and Rad51 generally do not colocalise, but Rad51 and RPA are frequently colocalised in aggregates, with more than $90 \%$ of Rad51 aggregates colocalising with RPA (Fig. 7c), consistent with the suggestion that the Rad51 aggregates that form in srs 2 mutants reflect the presence of abnormal recombination events.

\section{Altered recombination intermediates in srs 2 mutants}

The above analysis indicates that aggregates of Rad51 do not form until cells exit from pachytene, which is also the time that $\mathrm{dHJ}$-containing recombination intermediates (joint molecules (JMs)) are resolved as COs (Allers and Lichten 2001; Sourirajan and Lichten 2008). To test the suggestion that Rad51 aggregate formation might be associated with abnormal JM metabolism, molecular analysis of recombination intermediates and products was performed, using a DNA isolation method that preserves dHJ intermediates (Allers and Lichten 2000). Southern blots were used to detect events at a URA3-ARG4 recombination reporter (Jessop et al. 2005) inserted on the left arm of chromosome III (Jessop et al. 2005; Fig. 8; Supplementary Fig. S3a). While DSB levels were similar in $s r s 2$ and $S R S 2$ strains (Supplementary Fig. S3b), a marked deficit in levels of detectable JMs (4- to 7-fold) was observed in srs 2 mutants (Fig. 8a, b). Despite the apparent reduction in JMs, which are crossover precursors (Allers and Lichten 2001), crossovers were recovered at similar levels from wild-type and srs 2 mutant cells (Fig. $8 \mathrm{c})$.

We considered two possible explanations for how steady-state levels of JMs could be reduced so markedly without substantially affecting CO levels. First, JM 
Fig. 7 Rad51 aggregates frequently colocalise with RPA. a Representative images of: (i) a nucleus with both Rad51 and Rfa1 foci, with minimal colocalisation and (ii) a Rad51 aggregate colocalised with Rfa1. b RPA colocalisation with Rad51 foci across a time course. Colocalisation between $\operatorname{Rad} 51$ foci and Rfa1 is infrequent. $\mathbf{c}$ RPA colocalisation with Rad51 aggregates in the same experiment. Almost all Rad51 aggregates that form in $s r s 2-m d$ cells colocalise with either foci or aggregates of Rfa1; > 100 nuclei were scored for all time points, except for $S R S 2,7 \mathrm{~h}$ and srs2- $m$ d, $0 \mathrm{~h}$ (70 and 72 nuclei, respectively) a
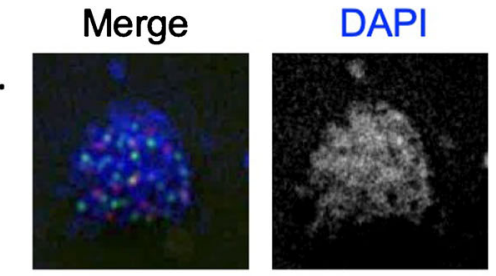

ii.
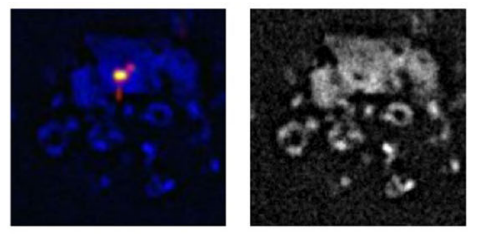

\section{b}

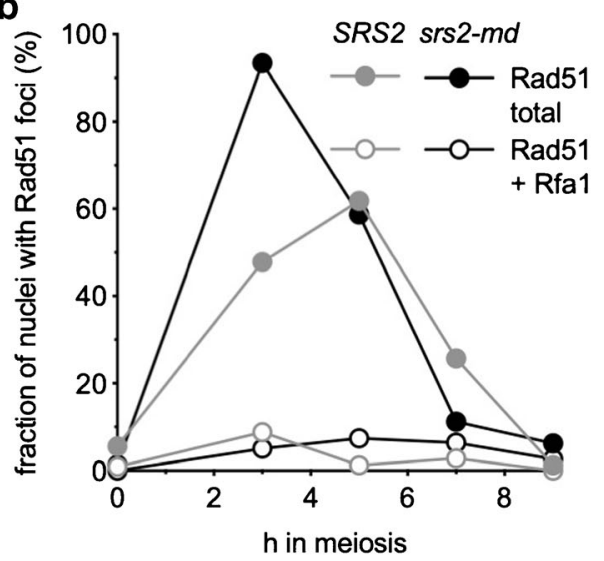

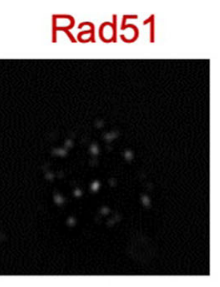
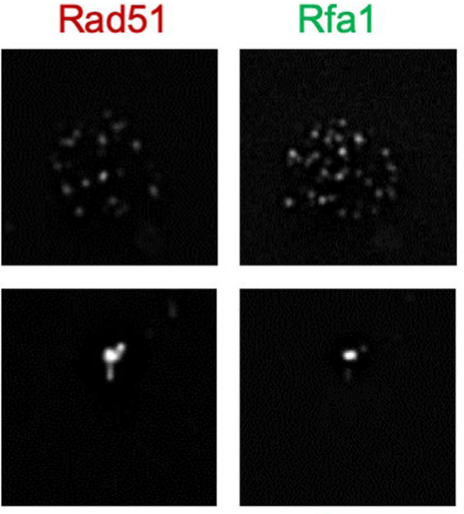

$5 \mu \mathrm{m}$

c

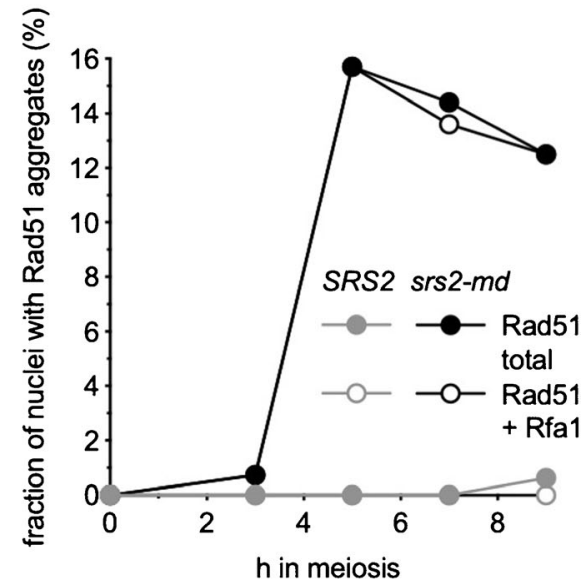

resolution might be accelerated, such that the average JM lifespan in srs 2 mutants was four to eight times shorter than in wild type. Second, JMs formed in srs 2 mutants might contain structural differences (such as nicked Holliday junctions) that make them unstable, either in vivo or during the DNA purification protocol used here. To test the first suggestion, JMs were measured in DNA isolated from resolution-defective $n d t 80 \Delta$ mutants using the same protocol, and were found to be both delayed and substantially reduced in $s r s 2 n d t 80 \Delta$ relative to $S R S 2$ $n d t 80 \Delta$. Thus, at least some of the difference between SRS2 and $s r s 2$ must be due to factors that affect JM structure or stability, rather than resolution. Consistent with this suggestion, loss of Srs2 activity resulted in a substantial increase (1.6-fold, average of 6-9 h) in the fraction of JMs in resolution-defective $n d t 80 \Delta$ mutants that contained more than two chromatids (multichromatid JMs; Fig. 8).

To test the second suggestion of increased lability of JMs formed in srs 2 mutants, the DNA isolation protocol was modified to include psoralen crosslinking, which has the potential to preserve otherwise unstable intermediates (Kaur et al. 2018). The addition of psoralen crosslinking resulted in recovery of JMs in similar levels from SRS2 and $s r s 2$ strains (Fig. 8e), supporting the suggestion that Srs2 activity is important for normal JM formation and stability.

\section{Discussion}

While multiple studies have examined roles for the multifunctional $S$. cerevisiae helicase Srs2 in DNA replication, repair and recombination during the mitotic cell cycle (Niu and Klein 2017), considerably less is known about Srs2's function during meiosis. Previous studies had shown that loss of Srs2 activity causes delays and defects in meiotic nuclear division, as well as reduced sporulation and spore viability (Palladino and Klein 1992; Sasanuma et al. 2013b). Our current study and an accompanying study (Sasanuma et al. 2019) have identified recombination abnormalities in meiosis I prophase that are likely the cause of abnormal nuclear division in $s r s 2$ mutants.

We find that $s r s 2$ mutants display multiple meiotic defects at both the cellular and molecular level, regardless of whether the mutants examined confer a chronic loss of Srs 2 activity (srs2 $\Delta$ and $\operatorname{srs2-101)}$ or a loss of $\operatorname{Srs} 2$ specifically during meiosis $(s r s 2-m d)$. These and other srs 2 mutant phenotypes are Spo11 dependent (Fig. S2a, c; Fig. 4; Sasanuma et al. 2019), indicating that abnormal recombination intermediates are a likely cause. A minority of srs 2 mutant cells (21-27\%) do not divide their nuclei (Fig. 1) and do not separate SPBs (Fig. 2c), consistent with a DNA damage-induced meiotic progression arrest before exit from pachytene. Cells that do 
a $\quad S R S 2$

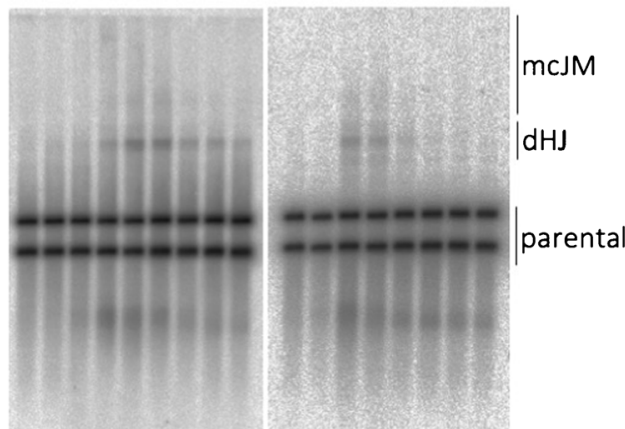

02345678923456789

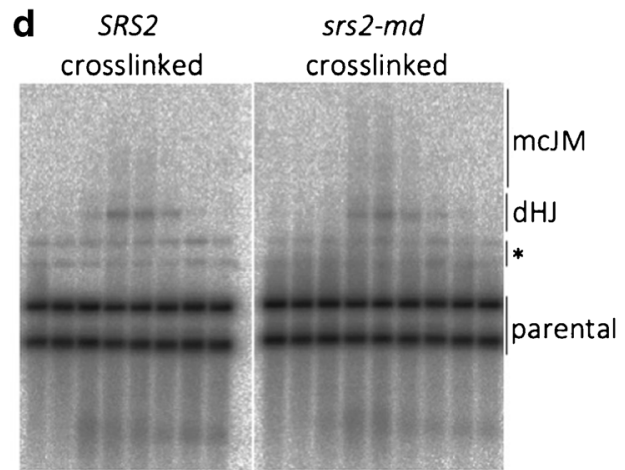

02345678023456789

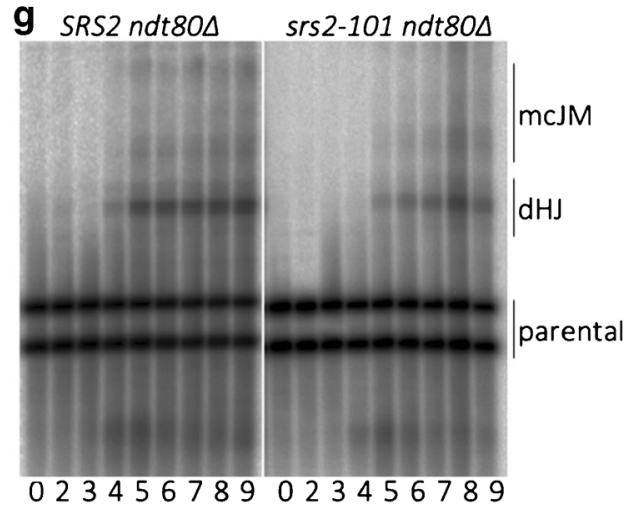

b

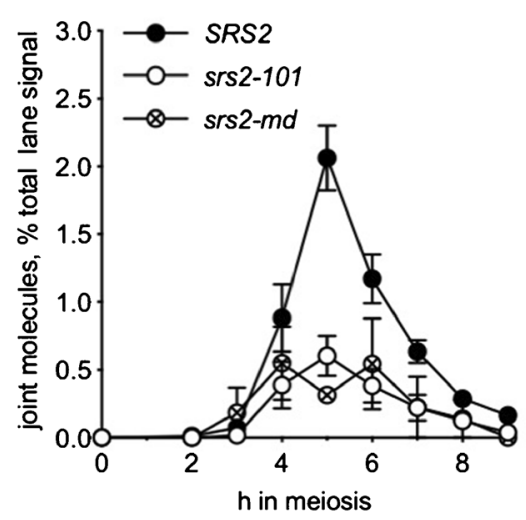

e

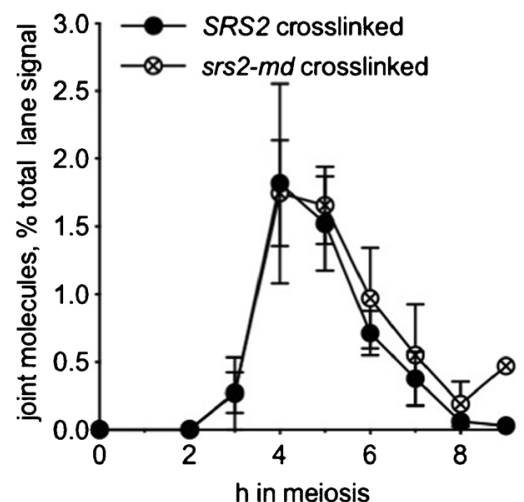

h

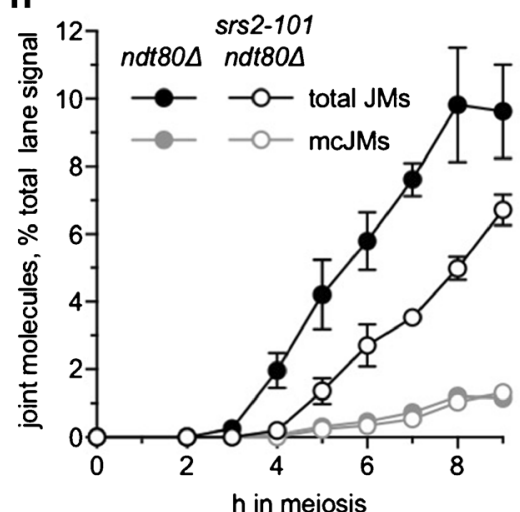

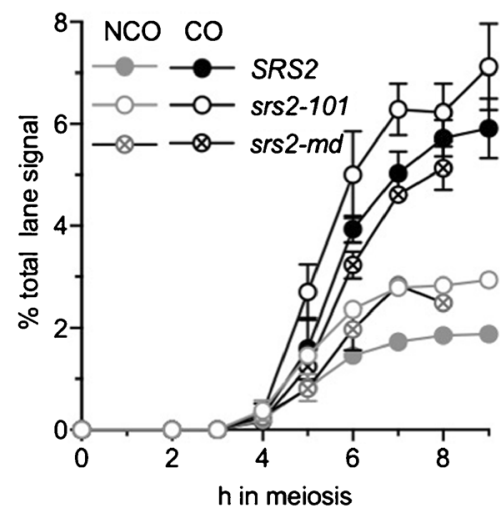

$\mathbf{f}$

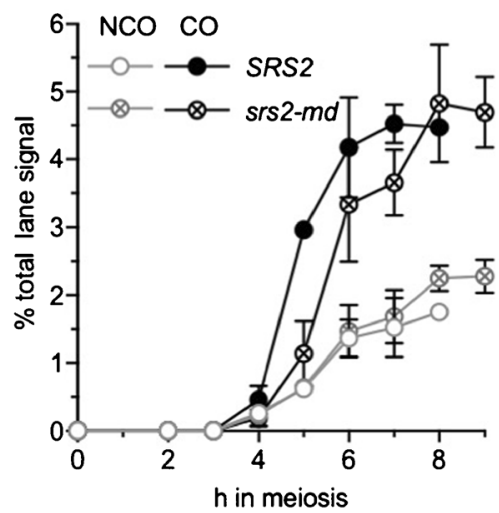

i

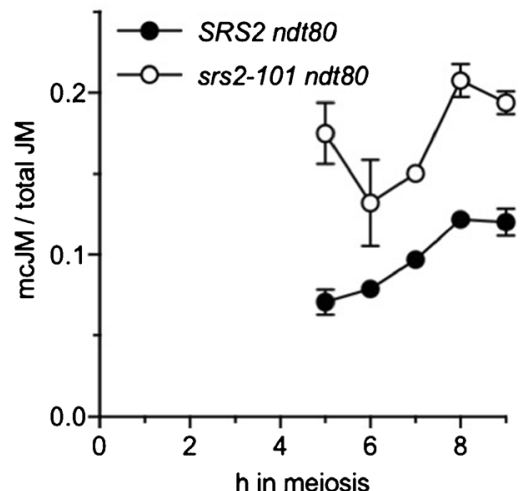

Fig. 8 Differences between recombination intermediates (JMs) formed in the presence and absence of Srs2 activity. a Southern blots of XmnI digests of DNA from the indicated time after initiation of meiosis, probed to detect joint molecules ( $\mathrm{dHJ}$ - double Holliday junctions; mcJM, multichromatid joint molecules) at a recombination reporter on chromosome III (see Fig. Fig. S1). b Quantification of blots from $S R S 2 \quad(n=5$, data from (De Muyt et al. 2012; Kaur et al. 2015) and one additional replicate; error bars denote SEM), srs2-101 $(n=5$; error bars denote $\mathrm{SEM})$ and $s r s 2-m d(n=2$; error bars denote range). JM recovery is markedly reduced in the absence of Srs2 activity. c Crossovers are formed at similar levels in the presence and absence of Srs2 activity, despite the marked difference in JM recovery. Noncrossovers are recovered at $\sim 50 \%$ greater levels in srs 2 mutants than in wild type. d Detection of JMs, as in (a), in psoralen-crosslinked DNA samples. Bands marked with an asterisk are the products of crosslink-induced partial XmnI digestion. e Quantification of three gels from two sporulations; error bars denote SEM. Psoralen crosslinking restores parity in JM recovery to srs $2 \mathrm{mu}-$ tants. f Crossovers and noncrossovers from crosslinked samples. $\mathbf{g}$ Detection of JMs, as in (a), from JM resolution-defective $n d t 80$ mutants. h Quantification of gels. $n=2$; error bars denote range. Total JM appearance in srs 2 mutants is delayed and reduced $\sim 2$-fold, but mcJMs are similar in $S R S 2$ and $s r s 2$. i fraction of JMs that are mcJMs exit from pachytene and progress to nuclear division do so with an $\sim 1$ h delay (Fig. 1), even though SPB separation occurs with normal timing during meiosis I and meiosis II
(Fig. 2b, c). These cells display DNA bridges (Fig. 1f), sister centromere separation without nuclear division (Fig. 3), meiosis II SPB separation and spindle formation within a single 
nuclear mass (Fig. 2d, e) and substantial spore inviability (Fig. $1 \mathrm{~g}, \mathrm{~h})$. These latter phenotypes suggest frequent recombination-dependent chromosome entanglements preventing nuclear division, as is observed in other mutants that are unable to properly resolve recombination intermediates (De Muyt et al. 2012; Jessop and Lichten 2008; Kaur et al. 2015; Oh et al. 2008; Tang et al. 2015). In summary, the pleotropic nature of the meiotic nuclear division defects seen in srs 2 mutants are consistent with abnormal recombination intermediates being present both before and after cells exit from pachytene.

\section{Persistent abnormal recombination intermediates in srs2 mutants}

Srs2 is thought to disrupt or prevent formation of Rad51containing nucleoprotein filaments during the mitotic cell cycle (Niu and Klein 2017). The observation of persistent Rad51 aggregates in srs2 mutants (Fig. 4; Sasanuma et al. 2019) suggests that Srs 2 has a similar function during meiosis. Interestingly, while aggregate formation does not require progression through meiosis I (Sasanuma et al. 2019), the absence of aggregates from $n d t 80 \Delta$ mutants, and from NDT80 cells with foci or linear arrays of the SC protein Zip1 (Figs. 5b and 6; Sasanuma et al. 2019), indicates that Rad51 aggregates do not form until cells have exited from pachytene and disassembled SC. Rad51 strand exchange activity is inhibited before pachytene exit (Subramanian et al. 2016), and Rad51 aggregate formation is greatly reduced in $\operatorname{srs} 2 \mathrm{rad} 51-I I 3 A$ mutants (Fig. 5b), which can form Rad51-DNA filaments but not catalyse strand exchange activity (Cloud et al. 2012). Thus, the appearance of Rad51 aggregates after exit from pachytene indicates that Rad51 strand exchange activity is necessary for this srs 2 mutant phenotype. Notably, the frequent colocalisation of aggregates of Rad51 and the RPA subunit Rfa1, observed in srs 2 mutants but rarely during normal meiosis (Fig. 7), suggests these aggregates form on abnormal recombination intermediates, most likely associated with stalled recombination events that are impeding normal nuclear division.

We applied two tests to determine if the Rad51 aggregates were likely to be associated with normal or abnormal recombination events. First, we deleted the Mek1 kinase, which during normal meiosis directs repair of Spo 11-DSBs away from the sister chromatid and towards the homologue (Callender et al. 2016; Niu et al. 2005; Niu et al. 2009). Secondly, we deleted Sae2, which is required for resection of Spo11-DSB ends during meiosis I prophase (McKee and Kleckner 1997; Prinz et al. 1997). Rad51 aggregation still

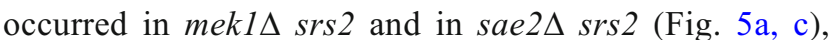
indicating that neither interhomologue strand invasion nor Sae2-mediated single-strand resection are required for post-pachytene Rad51 aggregation in srs 2 cells. Of particular note is the accumulation of Rad51 aggregates in resection-defective sae $2 \Delta \operatorname{srs} 2$ mutants; to account for this aggregate formation, we suggest that post-pachytene activation of Sae2-independent resection or helicase activities expose ssDNA at previously unresected DSBs, which can then participate in Rad51-mediated strand invasion.

In summary, these observations further support the hypothesis that the cytologically visible phenotypes of $s r s 2$ mutants might reflect the loss of suppression of Rad51 activity after pachytene (Fig. 9). Rad51 then decorates ssDNA from either or both the abnormal processing of normal intermediates created before and remaining after pachytene or abnormal recombination intermediates created after pachytene.

The question remains open as to whether these abnormal intermediates arise as a consequence of srs 2 mutant defects during early meiosis I prophase, when recombination normally occurs, or as a consequence of aberrant processing of residual lesions present after exit from pachytene, at the time when most DSB repair is complete.

\section{Early defects in recombination intermediate formation in srs 2 mutants}

Analysis of recombination intermediates at a URA3-ARG4 recombination reporter revealed that, DSBs are formed and repaired with normal kinetics in srs2 mutants (Fig. S3b), and both crossover and noncrossover recombinants were formed in $s r s 2$ mutants at levels approximating those seen in wild type. Thus, in contrast with what is seen in studies of vegetatively growing cells, Srs2 does not appear to have either pro- or anti-crossover function during meiosis. However, JMs, which are crossover precursors, were recovered from $\operatorname{srs} 2$ mutants at reduced levels when DNA was extracted using a protocol that uses multivalent cations to stabilise JMs but at normal levels when DNA was also psoralen-crosslinked before extraction (Fig. 8). This suggests that the JMs present in $s r s 2$ mutant cells have structures differing from those in wild type, and that the former are differentially lost during extraction in the absence of crosslinking. Loss of Srs2 activity results in both delays and reductions in recovery of stable JMs accumulating in resolution-defective $n d t 80$ cells, and the proportion of multichromatid JMs, which form when DSB ends interact with more than one repair template (Oh et al. 2007), is also increased. These findings suggest that many of the JMs formed in srs 2 mutants have less-stable structures than $\mathrm{JMs}$ formed in wild-type cells, possibly reflecting a failure to form fully ligated double Holliday junctions. These unstable JMs may be derived from a yet uncharacterised Srs2-dependent, Dmc1-independent pathway for meiotic DSB repair, suggested by observations that more 
unrepaired DSBs accumulate in $s r s 2 d m c 1$ double mutants than in SRS2 dmcl (ASHG and T-CC, unpublished observations).

\section{Concluding remarks}

Taken together, our data and the data of Sasanuma et al. (Sasanuma et al. 2019) indicate that Srs2 has an important role in recombination biochemistry throughout meiosis I prophase (Fig. 9). We propose that a major function of Srs2 during meiosis is to limit residency of Rad51 on Spo11-initiated DSBs. In the absence of Srs2 activity, increased Rad51 occupancy may reduce the ability of DSB ends to complete dHJ formation, both because fewer binding sites are available for Dmcl filament formation, and because Rad51 strand invasion activity is inhibited during early meiosis I prophase (Busygina et al. 2008; Callender et al. 2016; Niu et al. 2009; Tsubouchi and Roeder 2006). When srs 2 mutant cells exit from pachytene, relief of this inhibition (Subramanian et al. 2016) might allow transient formation of fully ligated $\mathrm{dHJ}$ intermediates before resolution as crossovers; alternatively, recombination intermediates formed in srs 2 mutants may not be fully ligated but can still can be resolved as COs upon exit from pachytene (Whitby 2005). We also suggest that, in srs 2 mutants, Rad51 aggregates that form upon exit from pachytene reflect the persistence of lesions that seed further $\operatorname{Rad} 51$ accumulation in the absence of Srs2 translocase; whether these are aberrant events normally resolved by Srs2, unresolvable intermediates formed before exit from pachytene, or intermediates formed de novo by DSBs present after pachytene exit, remains to be determined. The frequent, Spo11-dependent formation of Rad51 aggregates in srs 2 sae2 mutant cells (Fig. 5c), which are not expected to undergo resection or strand invasion before exit from pachytene, most likely reflects such post-pachytene DSB processing, either through DSB end destabilisation by high Rad51 residency or through end resection by nucleases or other activities that are derepressed after pachytene exit.

Srs2 belongs to the highly conserved UvrD helicase family, which has at least one representative in most organisms (Lorenz 2017; Niu and Klein 2017). Loss of the Srs2like Fbh1 protein in Schizosaccharomyces pombe, which also has Rad51 removal activity, confers meiotic defects similar to those seen in budding yeast, including reduced spore viability, meiotic nuclear division defects, and persistent Rad51 foci, without affecting frequencies of crossovers or noncrossovers among viable progeny (Sun et al. 2011). Interestingly, the human Fbh1 orthologue, when expressed in budding yeast, suppresses many of the mitotic recombination defects and DNA damage sensitivity of $s r s 2$ mutants, suggesting that hFBH1 may have Rad51removing activity, as well (Chiolo et al. 2007). It will be of considerable interest to determine the molecular defects underlying the similar mutant phenotypes of budding yeast

\section{Pachytene and earlier}

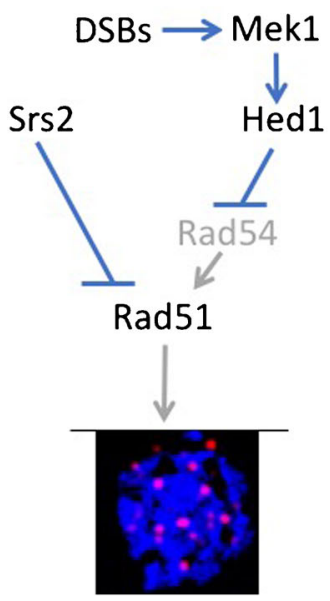

Fig. 9 Control of Rad51 aggregation during meiosis. During pachytene and earlier stages of meiosis, Rad51 activity is inhibited by two mechanisms. In one, meiotic DSBs activate the Mek1 kinase, stabilising Hed1, which in turn prevents association of the Rad54 cofactor with Rad51. In the second, Srs2 removes excess Rad51, limiting Rad51 accumulation to foci at DSBs. After exit from pachytene, DSBs are

\section{Post- pachytene}
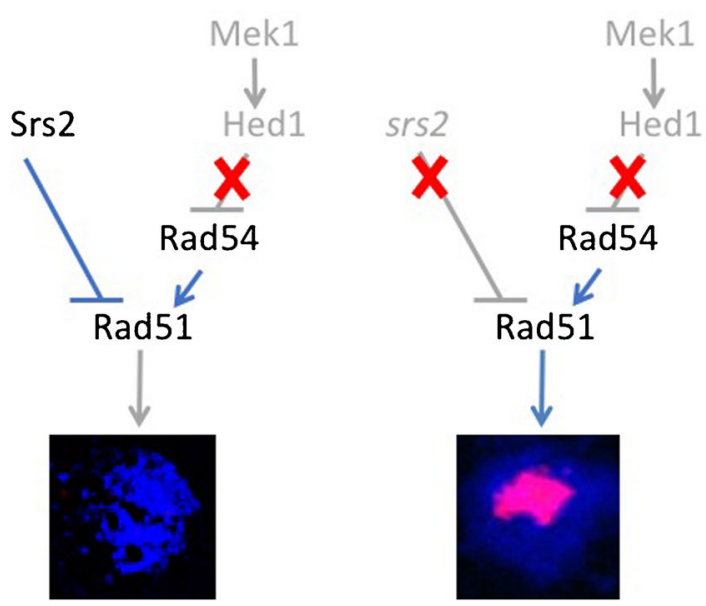

absent and Mek1-Hed1 dependent inhibition of Rad51 is inactive but the Rad51-removing activity of Srs2 remains, preventing accumulation of Rad51 on chromatin. In srs 2 mutants, neither Mek1-Hed1 nor Srs2dependent mechanisms prevent Rad51 accumulation on chromatin and aggregates accumulate 
$s r s 2$ and fission yeast $f b h 1^{-}$mutants, and to determine if the vertebrate protein has similar functions.

\section{Materials and methods}

\section{Yeast strains}

All yeast strains (Supplementary Table S1) are derived from SK1 (Kane and Roth 1974) by either transformation or genetic crosses. The $s r s 2-m d$ meiotic depletion allele ( $p C L B 2-3 H A-$ $S R S 2$ ) inserts CLB2 promoter sequences and a triple influenza hemagglutinin epitope tag immediately upstream of SRS2 coding sequences and was constructed by amplification of $p C L B 2-3 H A$ sequence from pAG335 (a gift from Monica Boselli) with primers containing $50 \mathrm{nt}$ targeting the SRS2 locus. Srs2Clb2ptagF: GAGTATCATTCCAATTTGAT C T T T C T T C T A C C G G T A C T T A G G G ATAGCAAtcgatgaattcgagctcg; Srs2CClb2ptagR: GTATTTAACTGGGATACTAAATGCAACCAAAG ATCATTGTTC GACGACATgcactgagcagcgtaatctg, where lowercase letters correspond to plasmid sequences. CNM67$m$ Cherry and GFP-TUB1 tag constructs were from AMY 6969 and AMY6706, respectively (a gift from Adele Marston). Zip1-GFP has been described (White et al. 2004). The RFA1-GFP allele inserts GFP sequences immediately downstream of RFA1 coding sequences and was constructed by amplification of GFP sequence from pKT127 (Sheff and Thorn 2004) with primers containing $50 \mathrm{nt}$ targeting the RFA1 locus: RFAChrGFP_F: GGGCTGAAGCCGAC TATCTTGCCGATGAGTTATCCAAGGCTTTGTTAGCT ggtgacggtgctggttta; RFAChrGFP_R: TTTCTCATATGTTA CATAGATTAAATAGTACTTGATTATTTGATACATTA tcgatgaattcgagctcg, where lowercase letters correspond to plasmid sequences.

\section{Spore viability}

Spore viability was determined by tetrad dissection. Diploid strains were sporulated $1-3$ days, $30{ }^{\circ} \mathrm{C}$ in patches on $1 \%(w /$ v) potassium acetate, $2 \%(w / v)$ agar plates, digested $15 \mathrm{~min}$, $30{ }^{\circ} \mathrm{C}$ in $1 \mathrm{M}$ sorbitol, $1 \%(w / v)$ glucose, $1 \mathrm{mg} / \mathrm{ml}$ zymolyase, dissected on YPAD agar (2\% peptone, $1 \%$ yeast extract, $2 \%$ glucose, $0.004 \%$ adenine, $2 \%$ agar, all $w / v$ ) and incubated for 2 days at $30^{\circ} \mathrm{C}$.

\section{Liquid sporulation}

All incubation temperatures were $30{ }^{\circ} \mathrm{C}$. All media components are $w / v$ unless otherwise indicated. For cytological studies, an overnight YPAD broth culture, inoculated with a single colony on YPAD agar, was grown with aeration overnight, and then was diluted to an $\mathrm{OD}_{600}$ of $\sim 0.3$ in BYTA ( $1 \%$ yeast extract, $2 \%$ tryptone, $1 \%$ potassium acetate, $50 \mathrm{mM}$ potassium phthalate) and incubated with aeration for $16 \mathrm{~h}$. The culture was harvested by centrifugation, washed with $200 \mathrm{ml} 1 \%$ potassium acetate, resuspended in $250 \mathrm{ml}$ SPM $(0.3 \%$ potassium acetate, $0.02 \%$ raffinose) with appropriate supplements to a final $\mathrm{OD}_{600}$ of $\sim 1.9$, and incubated with vigorous aeration. For molecular studies, sporulation in liquid was as described (Oh et al. 2009), using the 'Lichten' protocol.

\section{Cytological methods}

Nuclear divisions Of a culture, $0.5 \mathrm{ml}$ was mixed with $0.75 \mathrm{ml}$ ethanol and stored at $-20{ }^{\circ} \mathrm{C} ; 1 \mu \mathrm{l}$ of $0.5 \mathrm{mg} / \mathrm{ml} \mathrm{4} 4^{\prime}, 6$ diamidino-2-phenylindole (DAPI) was added, and samples were incubated at room temperature for $30 \mathrm{~s}$. Cells were harvested by centrifugation, resuspended in $0.2 \mathrm{ml} 50 \%$ glycerol, sonicated briefly if necessary to break up clumps and examined by epiflouresence microscopy. Cells with two nuclei were scored as having completed meiosis I and cells with three or four nuclei as having completed meiosis II.

Recombination protein foci Of a culture, $4.5 \mathrm{ml}$ was harvested by centrifugation and resuspended to $0.5 \mathrm{ml}$ in $1.0 \mathrm{M}$ sorbitol, $\mathrm{pH}$ 7. 1,4-Dithiothreitol and zymolyase were added to $24 \mathrm{mM}$ and $0.14 \mathrm{mg} / \mathrm{ml}$, respectively, and cells were spheroplasted by incubation at $37^{\circ} \mathrm{C}$ for 20 to $45 \mathrm{~min}$ with agitation, until the majority of cells lysed when mixed with an equal volume of $1.0 \%(w / v)$ sodium $N$-lauroylsarcosine; $3.5 \mathrm{ml}$ of Stop Solution (0.1 M MES, $1 \mathrm{mM}$ EDTA, $0.5 \mathrm{mM} \mathrm{MgCl} 2,1 \mathrm{M}$ sorbitol, $\mathrm{pH}$ 6.4) was added; cells were harvested by centrifugation, resuspended in $100 \mu \mathrm{l}$ Stop Solution and distributed between four ethanol-cleaned glass microscope slides. Twenty microlitres of fixative $(4.0 \%(w / v)$ formaldehyde, $3.8 \%(w / v)$ sucrose, $\mathrm{pH} 7.5$ ) was added to each slide, followed by $40 \mu \mathrm{l}$ of $1 \%$ Lipsol with light mixing. A further $40 \mu \mathrm{l}$ of fixative was added, and the mixture was spread across the slide. All subsequent steps were at room temperature, unless otherwise indicated. Slides were incubated for $30 \mathrm{~min}$ in a damp chamber, and then allowed to air dry. Once dry, slides were washed in $0.2 \%(v / v)$ PhotoFlo (Kodak) and then in water and allowed to air-dry slightly. Slides were washed once in $0.025 \%$ Triton X100 in phosphate-buffered saline (PBS) for $10 \mathrm{~min}$ and twice for $5 \mathrm{~min}$ in PBS. Slides were blocked with 5\% skimmed milk (Sigma) in PBS for $1-4 \mathrm{~h}$ at $37^{\circ} \mathrm{C}$; excess liquid was removed and slides were placed horizontally in a damp chamber. Mouse anti-yeast Rad51 antibody (Santa Cruz, sc-133,089, 1:200 in 1\% skim milk, PBS) was added at $150 \mu \mathrm{l} /$ slide, and slides were incubated at $4{ }^{\circ} \mathrm{C}$ overnight. Slides were washed three times in PBS ( 5 min each) and incubated with secondary antisera (AlexaFluor594-conjugated goat anti-mouse antibody; Life Technologies A11005; 1:1000 in 1\% skimmed milk, PBS), $150 \mu \mathrm{l}$ per slide, for 1-2 $\mathrm{h}$ in a damp chamber. Slides were washed three times with PBS (5 min each), cover 
slips were affixed using Vectashield mounting medium with DAPI (Vector Laboratories), sealed with clear varnish and imaged on a DeltaVision microscope $(z=12-15$, exposure times: RD-TP-RE $=1.0 \mathrm{~s}$, DAPI $=0.05-1.0 \mathrm{~s}, \mathrm{FITC}=1.0 \mathrm{~s}$ for Rfa1-GFP colocalisation experiments). Images were deconvolved by SoftWoRx software using standard settings and the number of cells with Rad51 or Rfa1 foci or aggregates counted. Aggregates were identified as being at least 6 pixels $(0.39 \mu \mathrm{m})$ wide, using Image J software.

Spindle pole bodies To reduce disruption of the DAPI signal during the spreading process, cells were formaldehyde-fixed before spheroplasting; $0.5 \mathrm{ml}$ of $37 \%(v / v)$ formaldehyde was added to $4.5 \mathrm{ml}$ of meiotic culture, and cells were incubated at room temperature for $30 \mathrm{~min}$. Cells were harvested by centrifugation, washed with $5 \mathrm{ml} 1 \%(w / v)$ potassium acetate and were then processed as above for recombination protein detection through the PhotoFlo/water wash steps. Cover slips were affixed using Vectashield mounting medium with DAPI (Vector Laboratories), sealed with clear varnish and imaged on a DeltaVision microscope $(z=12-24$, Exposure times: FITC $=1.0 \mathrm{~s}$, RD-TP-RE $=1.0 \mathrm{~s}$, DAPI $=0.05-1.0 \mathrm{~s}$ ). Images were deconvolved by SoftWoRx software using standard settings and the number of RFP (SPB) foci and DAPI signals per cell were counted, using GFP tubulin as an additional signal where necessary.

\section{Recombination intermediate and product analysis}

DNA was extracted, displayed on Southern blots and hybridised with radioactive probe as described, either without (Oh et al. 2009); 'Lichten lab' protocol) or with prior psoralen crosslinking (Kaur et al. 2018). JMs were detected using XmnI digests probed with +156 to +1413 of $A R G 4$ coding sequences. DSBs, NCOs and COs were detected using EcoRI-XhoI digests probed with + 539 to +719 of HIS4 coding sequences. Radioactive signal on blots was detected using either a Fuji LAS-3000 or a GE Typhoon FLA-9500 phosphorimager and was quantified using Fuji Image Guage v4.22 software.

\section{Protein extraction and western blots}

Samples containing 5-10 $\mathrm{OD}_{600}$ of cells were harvested by centrifugation, washed in $1 \mathrm{ml}$ water, and flash frozen in liquid nitrogen. The pellet was stored at $-80{ }^{\circ} \mathrm{C}$ for at least $2 \mathrm{~h}$ and was then resuspended in $150 \mu \mathrm{l}$ of $1.85 \mathrm{M} \mathrm{NaOH}, 7.5 \%(v / v)$ $\beta$-mercaptoethanol and incubated on ice for $15 \mathrm{~min}$. One hundred fifty microlitres of $55 \%$ trichloroacetic acid was added, and cells were incubated for a further $10 \mathrm{~min}$. Cells were harvested by centrifugation for $10 \mathrm{~min}$ at top speed in a microfuge and resuspended in $250 \mu \mathrm{l}$ of $200 \mathrm{mM}$ Tris- $\mathrm{HCl}$ at $\mathrm{pH} 6.5,8 \mathrm{M}$ urea, 5\% (w/v) SDS, $1 \mathrm{mM}$ EDTA, $0.02 \%$ bromophenol blue, $5 \%(v / v) \beta$-mercaptoethanol, with $10 \mu \mathrm{l}$ of $25 \times$ protease inhibitor stock (Roche, 04693132001). If necessary, $10 \mu \mathrm{l}$ of $1.5 \mathrm{M}$ Tris $\mathrm{HCl}$ at $\mathrm{pH} 8.8$ was added to maintain $\mathrm{pH}$, as shown by the blue indicator in the suspension. Cells were heat shocked at $65^{\circ} \mathrm{C}$ for $10 \mathrm{~min}$, centrifuged for $1 \mathrm{~min}$ at top speed in a microfuge, and the supernatant was harvested. Protein samples were denatured at $95^{\circ} \mathrm{C}$ for $5 \mathrm{~min}$ in appropriate loading buffer and loaded into precast SDSPAGE gels (10\% polyacrylamide; Biorad). Gels were run at $40 \mathrm{~mA}$ for $45 \mathrm{~min}$ in $1 \times$ running buffer (Fisher). Gels were assembled into a sandwich with Hybond $\mathrm{C}$ nitrocellulose membrane (Amersham) and Whatman 3MM blotting paper, and gel contents were transferred by semi-dry transfer (Thermo Scientific Pierce Power Blotter) using Pierce 1-Step Transfer Buffer for $7 \mathrm{~min}$ or by wet transfer in $0.025 \mathrm{M}$ Tris Base, $0.15 \mathrm{M}$ Glycine, $2 \%(v / v)$ methanol at $150 \mathrm{~mA}$ for $2 \mathrm{~h}$ or at $16 \mathrm{~V}$ overnight (Biorad MiniProtean Tetra Cell). Membranes were rinsed in water. If necessary, the membrane was incubated $30 \mathrm{~s}$ in Ponceau stain (Sigma), and then washed in PBST (Sigma). Membranes were incubated in $5 \%(w / v)$ skimmed milk in PBS at $4{ }^{\circ} \mathrm{C}$ for $2-20 \mathrm{~h}$, then incubated in primary antibody in $1 \%(w / v)$ skimmed milk in PBS at the following concentrations for $2-20 \mathrm{~h}$ at $4{ }^{\circ} \mathrm{C}$ (anti-Srs2, Santa Cruz sc-1191, 1:2000; anti-PSTAIR, Sigma P6962, 1:2500). Membranes were washed $3 \times$ in PBS, 5 min each at RT, and incubated in horseradish peroxidase-conjugated secondary antibody in $1 \%(w / v)$ skimmed milk in PBS at the following concentrations for 30-120 min at RT (anti-goat, Santa Cruz sc-2020, 1:2500; anti-mouse, Santa Cruz sc-2005, 1:2500). Membranes were washed $3 \times$ in PBS, 5 min each at RT, incubated with $2 \mathrm{ml}$ high sensititivity ECL detection solution (Millipore) and blots were visualised on a GeneGnome chemiluminsescence imaging system.

Acknowledgements We thank Douglas Bishop, Monica Boselli, Bin $\mathrm{Hu}$, Adele Marston and Akira Shinohara for strains, reagents, discussion and communication of results in advance of publication and Matan Cohen for technical assistance in preparing DNA samples. Imaging was performed using the DeltaVision microscope at the Wolfson Light Microscopy Facility, University of Sheffield. This work was supported by BBSRC BB/K009346/1 to ASHG and by the Intramural Research Program at the Center for Cancer Research, National Cancer Institute, National Institutes of Health.

Open Access This article is distributed under the terms of the Creative Commons Attribution 4.0 International License (http:// creativecommons.org/licenses/by/4.0/), which permits unrestricted use, distribution, and reproduction in any medium, provided you give appropriate credit to the original author(s) and the source, provide a link to the Creative Commons license, and indicate if changes were made.

\section{References}

Allers T, Lichten M (2000) A method for preparing genomic DNA that restrains branch migration of Holliday junctions. Nucleic Acids Res 28:e6-e66 
Allers T, Lichten M (2001) Differential timing and control of noncrossover and crossover recombination during meiosis. Cell 106:47-57

Andersen SL, Sekelsky J (2010) Meiotic versus mitotic recombination: two different routes for double-strand break repair: the different functions of meiotic versus mitotic DSB repair are reflected in different pathway usage and different outcomes. Bioessays 32:10581066

Bishop DK, Park D, Xu L, Kleckner N (1992) DMC1: a meiosis-specific yeast homolog of $E$. coli recA required for recombination, synaptonemal complex formation, and cell cycle progression. Cell 69:439-456

Brill SJ, Stillman B (1991) Replication factor-A from Saccharomyces cerevisiae is encoded by three essential genes coordinately expressed at S phase. Genes Dev 5:1589-1600

Busygina V, Sehorn MG, Shi IY, Tsubouchi H, Roeder GS, Sung P (2008) Hed1 regulates Rad51-mediated recombination via a novel mechanism. Genes Dev 22:786-795

Byers B, Goetsch L (1975) Behavior of spindles and spindle plaques in the cell cycle and conjugation of Saccharomyces cerevisiae. J Bacteriol 124:511-523

Bzymek M, Thayer NH, Oh SD, Kleckner N, Hunter N (2010) Double Holliday junctions are intermediates of DNA break repair. Nature 464:937-941

Callender TL, Laureau R, Wan L, Chen X, Sandhu R, Laljee S, Zhou S, Suhandynata RT, Prugar E, Gaines WA, Kwon YH, Börner GV, Nicolas A, Neiman AM, Hollingsworth NM (2016) Mek1 down regulates Rad51 activity during yeast meiosis by phosphorylation of Hed1. PLoS Genet 12:e1006226

Carballo JA, Johnson AL, Sedgwick SG, Cha RS (2008) Phosphorylation of the axial element protein Hop1 by Mec1/Tel1 ensures meiotic interhomolog recombination. Cell 132:758-770

Chen H, Lisby M, Symington LS (2013) RPA coordinates DNA end resection and prevents formation of DNA hairpins. Mol Cell 50: $589-600$

Chiolo I, Saponaro M, Baryshnikova A, Kim JH, Seo YS, Liberi G (2007) The human F-box DNA helicase FBH1 faces Saccharomyces cerevisiae Srs2 and postreplication repair pathway roles. Mol Cell Biol 27:7439-7450

Chu S, Herskowitz I (1998) Gametogenesis in yeast is regulated by a transcriptional cascade dependent on Ndt80. Mol Cell 1:685-696

Chu S, DeRisi J, Eisen M, Mulholland J, Botstein D, Brown PO, Herskowitz I (1998) The transcriptional program of sporulation in budding yeast. Science 282:699-705

Cloud V, Chan YL, Grubb J, Budke B, Bishop DK (2012) Rad51 is an accessory factor for Dmc1-mediated joint molecule formation during meiosis. Science 337:1222-1225

De Muyt A, Jessop L, Kolar E, Sourirajan A, Chen J, Dayani Y, Lichten M (2012) BLM helicase ortholog Sgs1 is a central regulator of meiotic recombination intermediate metabolism. Mol Cell 46:43-53

Dupaigne P, Le Breton C, Fabre F, Gangloff S, Le Cam E, Veaute X (2008) The Srs2 helicase activity is stimulated by Rad51 filaments on dsDNA: implications for crossover incidence during mitotic recombination. Mol Cell 29:243-254

Elango R, Sheng Z, Jackson J, DeCata J, Ibrahim Y, Pham NT, Liang DH, Sakofsky CJ, Vindigni A, Lobachev KS, Ira G, Malkova A (2017) Break-induced replication promotes formation of lethal joint molecules dissolved by Srs2. Nat Commun 8:1790

Fox C, Zou J, Rappsilber J, Marston AL (2017) Cdc14 phosphatase directs centrosome re-duplication at the meiosis I to meiosis II transition in budding yeast. Wellcome Open Res 2:2

Gasior SL, Wong AK, Kora Y, Shinohara A, Bishop DK (1998) Rad52 associates with RPA and functions with Rad55 and Rad57 to assemble meiotic recombination complexes. Genes Dev 12:2208-2221

Hays SL, Firmenich AA, Massey P, Banerjee R, Berg P (1998) Studies of the interaction between Rad52 protein and the yeast single-stranded DNA binding protein RPA. Mol Cell Biol 18:4400-4406
Heyting C (1996) Synaptonemal complexes: structure and function. Curr Opin Cell Biol 8:389-396

Ira G, Malkova A, Liberi G, Foiani M, Haber JE (2003) Srs2 and Sgs1Top3 suppress crossovers during double-strand break repair in yeast. Cell 115:401-411

Jaspersen SL, Huneycutt BJ, Giddings TH Jr, Resing KA, Ahn NG, Winey M (2004) Cdc28/Cdk1 regulates spindle pole body duplication through phosphorylation of Spc42 and Mps1. Dev Cell 7:263274

Jessop L, Lichten M (2008) Mus81/Mms4 endonuclease and Sgs1 helicase collaborate to ensure proper recombination intermediate metabolism during meiosis. Mol Cell 31:313-323

Jessop L, Allers T, Lichten M (2005) Infrequent co-conversion of markers flanking a meiotic recombination initiation site in Saccharomyces cerevisiae. Genetics 169:1353-1367

Kadyk LC, Hartwell LH (1992) Sister chromatids are preferred over homologs as substrates for recombinational repair in Saccharomyces cerevisiae. Genetics 132:387-402

Kane SM, Roth R (1974) Carbohydrate metabolism during ascospore development in yeast. J Bacteriol 118:8-14

Kaniecki K, De Tullio L, Gibb B, Kwon Y, Sung P, Greene EC (2017) Dissociation of Rad51 presynaptic complexes and heteroduplex DNA joints by tandem assemblies of Srs2. Cell Rep 21:3166-3177

Kaur H, De Muyt A, Lichten M (2015) Top3-Rmi1 DNA single-strand decatenase is integral to the formation and resolution of meiotic recombination intermediates. Mol Cell 57:583-594

Kaur H, Ahuja JS, Lichten M (2018) Methods for controlled protein depletion to study protein function during meiosis. Method Enzymol 601:331-357

Keeney S, Giroux CN, Kleckner N (1997) Meiosis-specific DNA doublestrand breaks are catalyzed by Spo11, a member of a widely conserved protein family. Cell 88:375-384

Krejci L, Van Komen S, Li Y, Villemain J, Reddy MS, Klein H, Ellenberger T, Sung P (2003) DNA helicase Srs2 disrupts the Rad51 presynaptic filament. Nature 423:305-309

Lawrence CW, Christensen RB (1979) Metabolic suppressors of trimethoprim and ultraviolet light sensitivities of Saccharomyces cerevisiae rad6 mutants. J Bacteriol 139:866-876

Lichten M, Haber JE (1989) Position effects in ectopic and allelic mitotic recombination in Saccharomyces cerevisiae. Genetics 123:261-268

Liu J, Ede C, Wright WD, Gore SK, Jenkins SS, Freudenthal BD, Washington MT, Veaute X, Heyer W-D (2017) Srs2 promotes synthesis-dependent strand annealing by disrupting DNA polymerase $\delta$-extending D-loops. eLife 6:e22195

Lorenz A (2017) Modulation of meiotic homologous recombination by DNA helicases. Yeast 34:195-203

Marini V, Krejci L (2010) Srs2: the "Odd-Job Man" in DNA repair. DNA Repair 9:268-275

Marini V, Krejci L (2012) Unwinding of synthetic replication and recombination substrates by Srs2. DNA Repair 11:789-798

McKee AHZ, Kleckner N (1997) A general method for identifying recessive diploid-specific mutations in Saccharomyces cerevisiae, its application to the isolation of mutants blocked at intermediate stages of meiotic prophase and characterization of a new gene $S A E 2$. Genetics 146:797-816

Morrical SW (2015) DNA-pairing and annealing processes in homologous recombination and homology-directed repair. CSH Perspect Biol 7:a016444

Nassif N, Penney J, Pal S, Engels WR, Gloor GB (1994) Efficient copying of nonhomologous sequences from ectopic sites via P-elementinduced gap repair. Mol Cell Biol 14:1613-1625

Niu H, Klein HL (2017) Multifunctional roles of Saccharomyces cerevisiae Srs2 protein in replication, recombination and repair. FEMS Yeast Res 17 
Niu H, Wan L, Baumgartner B, Schaefer D, Loidl J, Hollingsworth NM (2005) Partner choice during meiosis is regulated by Hop1promoted dimerization of Mek1. Mol Biol Cell 16:5804-5818

Niu H, Wan L, Busygina V, Kwon Y, Allen JA, Li X, Kunz RC, Kubota K, Wang B, Sung P, Shokat KM, Gygi SP, Hollingsworth NM (2009) Regulation of meiotic recombination via Mek1-mediated Rad54 phosphorylation. Mol Cell 36:393-404

Oh SD, Lao JP, Hwang PY, Taylor AF, Smith GR, Hunter N (2007) BLM ortholog, Sgs1, prevents aberrant crossing-over by suppressing formation of multichromatid joint molecules. Cell 130:259-272

Oh SD, Lao JP, Taylor AF, Smith GR, Hunter N (2008) RecQ helicase, Sgs1, and XPF family endonuclease, Mus81-Mms4, resolve aberrant joint molecules during meiotic recombination. Mol Cell 31: 324-336

Oh SD, Jessop L, Lao JP, Allers T, Lichten M, Hunter N (2009) Stabilization and electrophoretic analysis of meiotic recombination intermediates in Saccharomyces cerevisiae. Methods Mol Biol 557: 209-234

Palladino F, Klein HL (1992) Analysis of mitotic and meiotic defects in Saccharomyces cerevisiae SRS2 DNA helicase mutants. Genetics 132:23-37

Petronczki M, Siomos MF, Nasmyth K (2003) Un ménage a quatre: the molecular biology of chromosome segregation in meiosis. Cell 112: 423-440

Prinz S, Amon A, Klein F (1997) Isolation of COM1, a new gene required to complete meiotic double-strand break-induced recombination in Saccharomyces cerevisiae. Genetics 146:781-795

Rong L, Palladino F, Aguilera A, Klein HL (1991) The hyper-gene conversion hpr 5-1 mutation of Saccharomyces cerevisiae is an allele of the SRS2/RADH gene. Genetics 127:75-85

Sasanuma H, Furihata Y, Shinohara M, Shinohara A (2013a) Remodeling of the Rad51 DNA strand-exchange protein by the Srs2 helicase. Genetics 194:859-872

Sasanuma H, Tawaramoto MS, Lao JP, Hosaka H, Sanda E, Suzuki M, Yamashita E, Hunter N, Shinohara M, Nakagawa A, Shinohara A (2013b) A new protein complex promoting the assembly of Rad51 filaments. Nat Commun 4:1676

Sasanuma H, Sakurai HSM, Furihata Y, Palmer L, Shinohara M, Shinohara A (2019) Srs2 helicase prevents the formation of toxic DNA damage during late prophase I of yeast meiosis. Chromosoma submitted
Sheff MA, Thorn KS (2004) Optimized cassettes for fluorescent protein tagging in Saccharomyces cerevisiae. Yeast 21:661-670

Sourirajan A, Lichten M (2008) Polo-like kinase Cdc5 drives exit from pachytene during budding yeast meiosis. Genes Dev 22:2627-2632

Subramanian VV, MacQueen AJ, Vader G, Shinohara M, Sanchez A, Borde V, Shinohara A, Hochwagen A (2016) Chromosome synapsis alleviates Mek1-dependent suppression of meiotic DNA repair. PLoS Biol 14:e1002369

Sun W, Lorenz A, Osman F, Whitby MC (2011) A failure of meiotic chromosome segregation in a $f b h 1 \Delta$ mutant correlates with persistent Rad51-DNA associations. Nucleic Acids Res 39:1718-1731

Szostak JW, Orr-Weaver TL, Rothstein RJ, Stahl FW (1983) The doublestrand-break repair model for recombination. Cell 33:25-35

Tang S, Wu MKY, Zhang R, Hunter N (2015) Pervasive and essential roles of the Top3-Rmil decatenase orchestrate recombination and facilitate chromosome segregation in meiosis. Mol Cell 57:607-621

Tsubouchi H, Roeder GS (2006) Budding yeast Hed1 down-regulates the mitotic recombination machinery when meiotic recombination is impaired. Genes Dev 20:1766-1775

Veaute X, Jeusset J, Soustelle C, Kowalczykowski SC, Le Cam E, Fabre F (2003) The Srs2 helicase prevents recombination by disrupting Rad51 nucleoprotein filaments. Nature 423:309-312

Whitby MC (2005) Making crossovers during meiosis. Biochem Soc Trans 33:1451-1455

White EJ, Cowan C, Cande WZ, Kaback DB (2004) In vivo analysis of synaptonemal complex formation during yeast meiosis. Genetics 167:51-63

Xu L, Ajimura M, Padmore R, Klein C, Kleckner N (1995) NDT80, a meiosis-specific gene required for exit from pachytene in Saccharomyces cerevisiae. Mol Cell Biol 15:6572-6581

Yang F, Wang PJ (2009) The mammalian synaptonemal complex: a scaffold and beyond. Genome Dyn 5:69-80

Zickler D, Kleckner N (1999) Meiotic chromosomes: integrating structure and function. Annu Rev Genet 33:603-754

Zickler D, Kleckner N (2016) A few of our favorite things: pairing, the bouquet, crossover interference and evolution of meiosis. Semin Cell Dev Biol 54:135-148

Publisher's note Springer Nature remains neutral with regard to jurisdictional claims in published maps and institutional affiliations. 